\title{
Performance evaluation of structures with reinforced concrete columns retrofitted with steel jacketing
}

\author{
Sergio Villar-Salinas ${ }^{a, *}$, Andrés Guzmán ${ }^{\mathrm{b}}$, Julian Carrillo ${ }^{\mathrm{c}}$

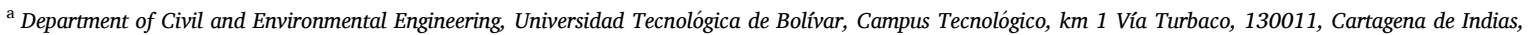 \\ Colombia \\ b Department of Civil and Environmental Engineering, Universidad del Norte, km 5 Vía Puerto Colombia, Área Metropolitana de Barranquilla, 081007, Barranquilla, \\ Atlántico, Colombia \\ ${ }^{\mathrm{c}}$ Department of Civil Engineering, Universidad Militar Nueva Granada, UMNG, Carrera 11 \#101-80, Edificio F, Piso 2, 110111, Bogotá D.C., 49300, Colombia
}

\section{A R T I C L E I N F O}

\section{Keywords:}

Seismic performance

Seismic retrofitting

RC buildings

Nonlinear modeling

Steel jacketing

\begin{abstract}
A B S T R A C T
Several existing reinforced concrete (RC) buildings fail to conform with current seismic codes, increasing its susceptibility to damage and collapse during earthquakes. A concern for building upgrading and rehabilitation has grown considerably in the last decades. However, there is limited information related to the seismic performance of RC buildings retrofitted with steel jacketing. Retrofitting of RC buildings leads to different techniques that have been developed in the last decades. The selection of adequate techniques commonly depends on desired performance levels, financial criteria, or other non-technical judgment. This paper assesses the seismic performance of a six-story RC building retrofitted with steel jacketing that is located in Cartagena de Indias (Colombia). The building was designed and constructed in 2010 without considering the requirements prescribed by the NSR-10 Colombian code. In 2017, another building collapsed in the same city for several non-compliances with Colombian seismic code. This investigation focuses on the seismic upgrading of the building, studying the influence of different material properties of the existing building and load scenarios on the building behavior. The proposed steel jacketing improves the compressive and flexural capacity of retrofitted columns, along with the ductility of the building.
\end{abstract}

\section{Introduction}

Several existing reinforced concrete (RC) buildings do not conform to current seismic codes, even in regions of high seismic hazard. Therefore, many of these buildings are susceptible to damage and even collapse during earthquakes [1,2]. Structural and non-structural damages and poor performance of RC buildings with code non-compliances have been observed after recent earthquakes [3]. Most of these damages haven been evidenced in RC columns with insufficient axial/shear loads capacity given by inadequate longitudinal/transversal reinforcement and dimensions, 90-degree hooks for stirrups at both ends of columns, inadequate detailing in beam-column joint regions, strong-beam and weak-columns, soft stories, weak stories, and poor quality construction $[4,5]$.

The concern for seismic upgrading and rehabilitation has grown in the last decades $[2,6,7]$ following structural and non-structural earthquake-induced damages observed after relevant seismic events in different parts of the world like Northridge (1994), Kobe (1995), Kocaeli (1999), Sichuan (2008), Chile (2010), Ecuador (2016) or Mexico (2017). In Colombia, the government adopted the earthquake-resistant Code for construction in Colombia NSR-10 [8]. This code prescribes criteria and minimum requirements for the design, construction, and technical supervision of new buildings. Also, the code offers design and revision guidelines for those buildings indispensable after an earthquake.

Buildings designed according to NSR-10 should be able to resist service loads and low-intensity earthquakes without damage; moderate earthquakes without structural damage, but possibly with some damage in non-structural elements; and strong earthquakes with damage of structural and non-structural elements, but without collapse [9]. Most of the earthquake-resistant codes, including the NSR-10 Colombian Code, establish general requirements for the assessment, upgrade, rehabilitation/retrofitting, and repairing of structural systems after an earthquake, and pre-existing buildings. Nevertheless, further research on the seismic performance of retrofitted RC buildings is needed. Although

\footnotetext{
* Corresponding author.

E-mail addresses: svillars@utb.edu.co (S. Villar-Salinas), faguzman@uninorte.edu.co (A. Guzmán), julian.carrillo@unimilitar.edu.co (J. Carrillo).
} 
concerns related to seismic upgrading and retrofitting has increased considerably in the last decades, there is a lack of knowledge of the global seismic performance of systems that have been retrofitted [2].

A significant understanding has been accomplished on the flexural and shear strengthening, and on confining individual structural elements, or bi-dimensional configurations of beam-column connections. However, limited information is available on the highly complex 3dimensional structural behavior [10]. Currently, there are few codes devoted to seismic strengthening of buildings. In consequence, engineering discernment is commonly based on assessment methods that are conceptually appropriate to the design of new structures, rather than assessing existing ones [11].

A literature review (2019) on retrofitting of RC buildings revealed different techniques developed in the last decades and calibrated through experimental and numerical research [12,13]. Steel bracings, masonry infills, and shear walls have shown the feasibility to increase the global strength and stiffness of elements and structures. However, there are several drawbacks to this approach, which includes excessive increment of stiffness. If this increment is not considered carefully using inelastic analysis and design process, it could decrease the ductility of structures and then affect the global behavior of the building. The need for new foundations or strengthening of the existing ones is usually a drawback. All these three techniques may demand a large space to place bracings and walls, and this affects functionality in excess [14].

External jacketing of columns and beam-column joints with composites made of Fiber-Reinforced Polymers (FRPs) has become a welldeveloped retrofitting technique for improving the seismic performance of sub-standard RC buildings [15-18]. The improvement on the deformation and shear strength capacity of jacketed members helps to prevent the fragile collapse mechanism of buildings with limited ductility. Nevertheless, the axial strength capacity keeps roughly constant [19]. The axial load variation on columns is an important subject to consider as the interaction between axial load and flexural-shear loads affects the seismic performance of structures. Purposely, most of the available research studies have contemplated, for easiness, a constant axial load. This simplification is a disadvantage of current assessment procedures of real structures $[10,20]$.

Another type of jacketing of columns and beam-column joints is based on steel elements. Different from FRP jacketed RC buildings, steel jacketing of columns and beam-column joints could improve the shear strength, the deformation capacity, and the global structural ductility and stiffness [21,22]. Besides, this technique could overcome the challenge of space limitations related to other techniques like steel bracings, masonry infills, or shear walls. The selection of an adequate retrofitting technique depends on desired performance levels, economic criteria, and non-technical judgment [13]. In this study, a steel jacketing of columns and beam-column joints is selected, considering the limitation of the building under study that is related to overstressed columns under service loads, unavailability of space for bracings, or walls, and the difficulty to build new foundations or to upgrade existing ones.

This paper shows the results of the seismic performance assessment and the retrofit design for a six-story RC building in Cartagena de Indias (Colombia). It is part of a research project that aims at studying the seismic performance of buildings not complying with service loads according to modern design codes. The building was designed and constructed as a six-story non-conforming to NSR-10 [8] in 2010. In 2017, another six-story building collapsed in the mentioned city for several non-compliances to Colombian seismic code. In consequence, some owners contracted the study to assess the seismic performance of existing buildings strictly considering elastic demand/capacity ratios and drifts, which is too limited.

This article deals with the effects of a selected steel jacketing retrofitting system on the original structure. The 3-dimensional building lateral strength, ductility, resistant base shear, the seismic response modification factor, $R$, and performance level [23,24] are studied using the capacity curves of both the existing building and the upgraded building. Besides, the increase of the columns compressive and flexural strength is set, using analytical expressions [25,26]. Finally, a parametric analysis of different concrete properties of the existing building, and load scenarios are provided.

\section{Materials and methods}

As a first step of the study (Fig. 1), initial surveys were performed to define the structural prototype. A geotechnical survey, non-destructive tests on RC elements, and As-built drawings elaboration were included. According to Vesic, Meyerhof, Terzaghi, and Hanzen's theories $[27,28]$, ultimate pressure is $1000 \mathrm{kPa}$; this soil bearing capacity is considerably high when compared to other soils of foundation in Cartagena. In the second step (Fig. 1), a preliminary linear-model of the existing building was made to check lateral drift ratios, beams/columns capacity ratios, and soil bearing capacity ratios. Thereby to identify the critical members.

The structural prototype is a six-story residential building in Cartagena de Indias, Colombia. As shown in Fig. 2, the architectural plan configuration is rectangular-shaped and irregular because axis 3 is not parallel to others, and axis 2 is not continuous all along the building length and the reduction of columns in frames along the " $\mathrm{Y}$ " direction. The plan of the building is $21.05 \mathrm{~m}$ long and $11.10 \mathrm{~m}$ wide. RC momentresisting frames in both directions provide a seismic force resistance system. Considering that design and "As-built drawings" were not available, a structural survey was developed in step 3 (Fig. 1) to investigate the reinforcement layout and to validate existing material properties. This step included a destructive test on RC elements (Fig. 3, Tables 1 and 2).

The hooks for beam/column stirrups are closed to $90^{\circ}$, not to $135^{\circ}$, as required by NSR-10 for seismic purposes. The columns' reinforcement is distributed symmetrically along the column sides.

The typical story height of the building is $2.80 \mathrm{~m}$. The specified compressive strength of concrete $\left(f^{\prime} c\right)$ is $21 \mathrm{MPa}$ and reinforcing steel bars comply with ASTM A615, Grade 60 steel $\left(f_{y}=420 \mathrm{MPa} ; E=200\right.$ GPa). According to NSR-10 code, the live load for living rooms is 1.8 $\mathrm{kPa}, 3.0 \mathrm{kPa}$ for stairs, and $5.0 \mathrm{kPa}$ for balconies. The dead load is 4.6 $\mathrm{kPa}$, which includes the weights of floor cover and the partition walls. Self-weight from other structural elements like the RC slab $(t=120$ $\mathrm{mm}$ ), columns, and beams are computed by the finite element analysis software (Section 3).

Fig. 4 shows the stress-strain material models used for push-over modeling. Concrete follows a non-linear uniaxial constant confinement model [29-31]. Steel reinforcement (rebar) and steel angles for retrofitting (Section 4) were modeled with a simplified version of the Ramberg-Osgood model [30,31] cited by Elkholy \& Ariss [32], using the software. The geotechnical survey displayed a high soil performance level, and therefore, the discussion of the performance of the building is centered on the structural non-compliances.

Lateral loads were computed as per NSR-10 code, chapter A.10: Assessment, retrofitting, or rehabilitation [24,33]. The seismic mass is equal to the dead load. A " $\mathrm{C}$ " soil profile, characterized by dense soil or soft stone with a shear wave velocity varying between 360 and $760 \mathrm{~m} / \mathrm{s}$ and STP number $\mathrm{N} \geq 50$, was considered for evaluating the bearing capacity. Site seismic parameters and the building location resulted in a design ground acceleration of $0.05 \mathrm{~g}$, associated with a $20 \%$ probability of exceedance in 50 years. This exceedance is permitted by NSR-10 only for assessment, upgrade, rehabilitation, or retrofitting of the structural system of pre-existing buildings. The assessment considered a response modification coefficient $(R)$ of two (2). The load combinations followed the Colombian code, which are the same combinations as ASCE 7-10.

The fourth step of the investigation (Fig. 1) consisted of the capacity assessment of the existing building. A review of the seismic performance literature related to building retrofitting was made before the selection of the retrofitting technique. An analysis of $M-\theta$ curves for RC members and capacity curves were considered to determine the performance 


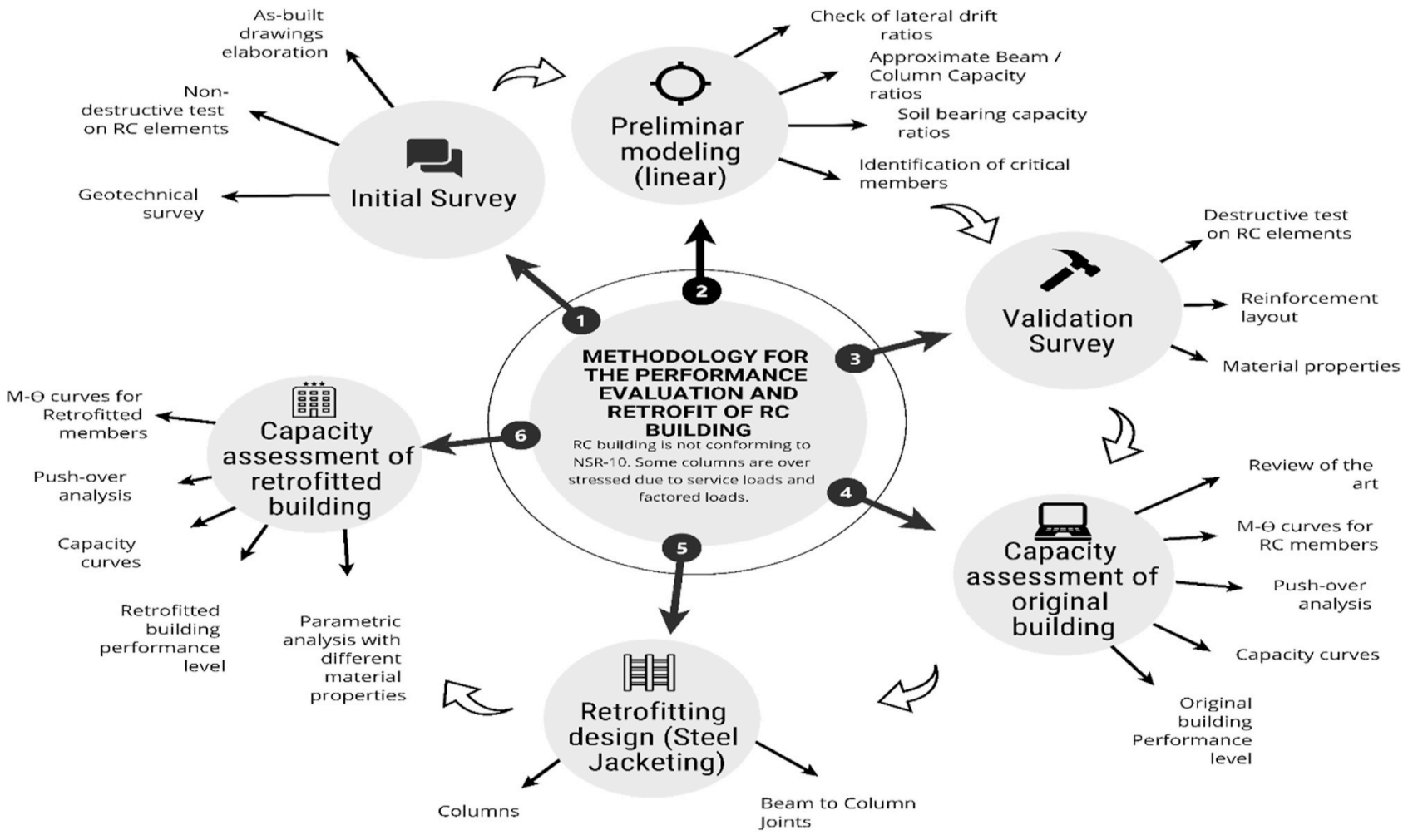

Fig. 1. Flowchart for assessment and retrofit of the RC model structure.

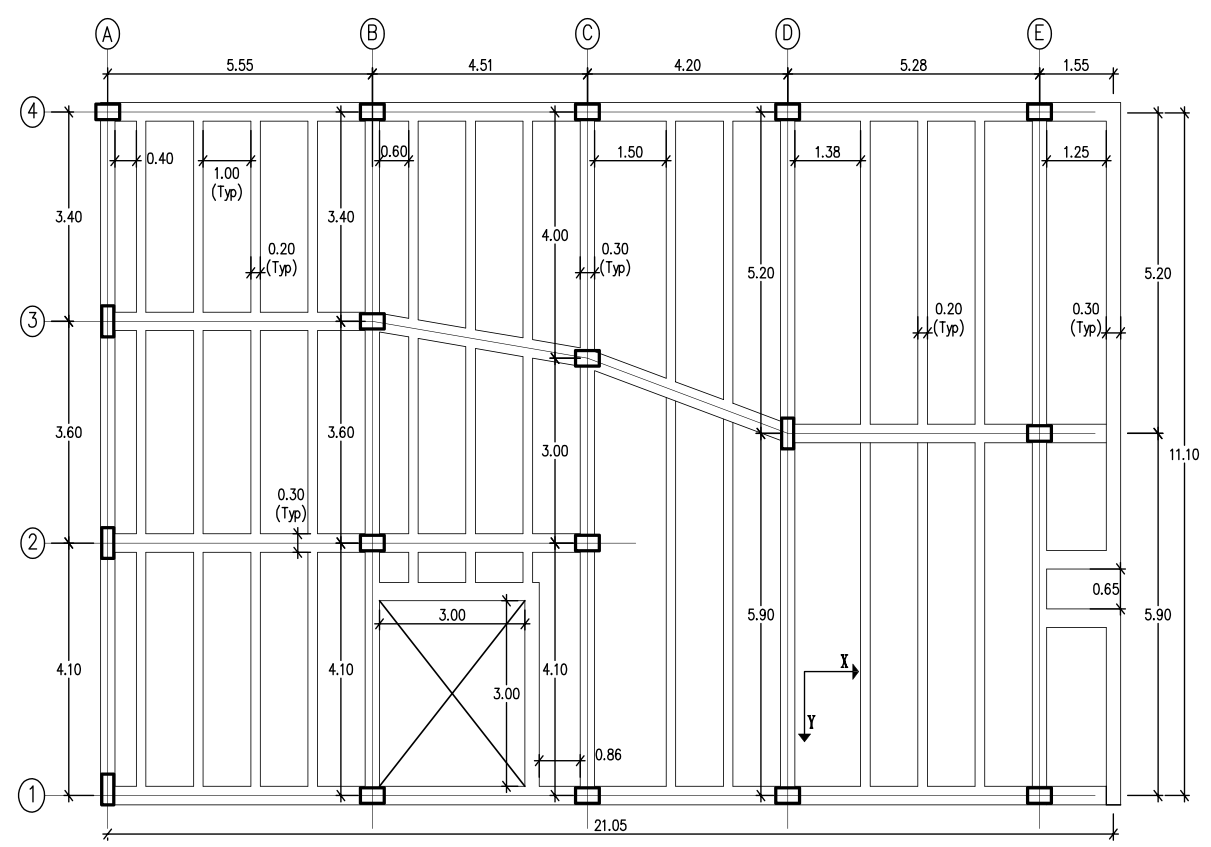

Fig. 2. Typical floor plan of the prototype building.

level of the original building. The retrofitting scheme was planned considering the strong column-weak beam principle. The steel jacketing details of RC columns and joints were determined in step five (Fig. 1) and are described in the following sections. Finally, the sixth step (Fig. 1) aimed at the capacity assessment of the retrofitted building. Capacity curves for the steel-jacketed RC building were obtained for the two main orthogonal directions. The effects of the selected steel jacketing scheme on the seismic performance of the building are discussed. Ductility, lateral strength, and the influence of different concrete properties of the existing structure are some parameters considered in the analysis.

\section{THEORY/CALCULATION of the existing building response}

The numerical model of the RC building was a 3D frame, rigidly connected at beam-column joints and diaphragms (Fig. 5). A Response Spectrum Analysis (RSA) and a Modal Push-over Analysis (MPA) were carried out using SAP2000v20 finite element method software [34]. 


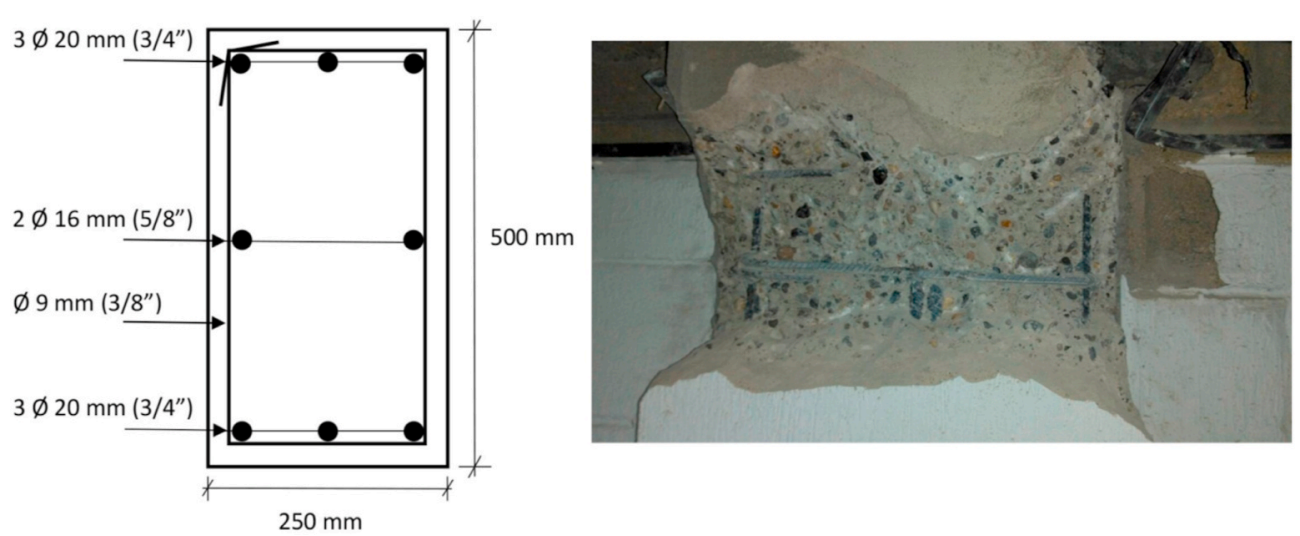

Fig. 3. Scarification of structural elements to determine existing reinforcement.

Table 1

Dimensions and reinforcement details of RC columns.

\begin{tabular}{|c|c|c|c|c|c|c|c|c|}
\hline \multirow[t]{3}{*}{ Column type } & \multirow[t]{3}{*}{ Dimensions (mm) } & \multicolumn{7}{|c|}{ Reinforcement } \\
\hline & & \multicolumn{3}{|c|}{ Longitudinal } & \multicolumn{4}{|c|}{ Transversal } \\
\hline & & Rebar & Area $\left(\mathrm{mm}^{2}\right)$ & Ratio (\%) & Rebar & Area $\left(\mathrm{mm}^{2}\right)$ & Spacing $(\mathrm{mm})$ & Confinement length (mm) \\
\hline Typical & $250 \times 500$ & $\begin{array}{l}6 \emptyset 20+ \\
2 \emptyset 16\end{array}$ & 2100 & 1.68 & $2 \varnothing 9$ & 138 & $100 / 200$ & 500 \\
\hline
\end{tabular}

Table 2

Dimensions and reinforcement details of RC beams.

\begin{tabular}{|c|c|c|c|c|c|c|c|}
\hline \multirow{3}{*}{$\begin{array}{l}\text { Beam } \\
\text { Type }\end{array}$} & \multirow[t]{3}{*}{ Dimensions (mm) } & \multicolumn{6}{|l|}{ Reinforcement } \\
\hline & & \multicolumn{2}{|l|}{ Longitudinal } & \multicolumn{4}{|c|}{ Transversal } \\
\hline & & Top rebar (ratio, $\rho$ ) & Bottom rebar (ratio, $\rho$ ) & Rebar & Area $\left(\mathrm{mm}^{2}\right)$ & Spacing (mm) & Confinement length (mm) \\
\hline Structural system (TYP.) & $300 \times 300$ & $2 \emptyset 20(0.0076)$ & $2 \varnothing 20(0.0076)$ & $2 \varnothing 9$ & 138 & 200 & 0 \\
\hline Joists & $200 \times 300$ & $2 \emptyset 16(0.0067)$ & $2 \emptyset 16(0.0067)$ & $2 \varnothing 9$ & 138 & 200 & 0 \\
\hline
\end{tabular}

Geometric and material non-linearities were considered to predict the behavior of the structure under static and dynamic loads.

\subsection{Modal Response Spectrum Analysis (MRSA)}

The MRSA is a standardized method to evaluate structures performance subjected to lateral loads. The following relevant parameters help to understand the structural behavior and response mechanisms.

\subsubsection{Lateral inter-story drift}

Lateral inter-story drift is computed as a percentage (\%) of story height. Fig. 6 shows the maximum values for the drifts along the main orthogonal directions of the structure (named $\mathrm{X}$ and $\mathrm{Y}$ ), for every story of the building. As shown in Fig. 6, lateral story drifts meet the drift limit specified by NSR-10 ( $1 \%$ of the total floor height). However, it shall be considered that seismic movements with a $20 \%$ probability of exceedance in 50 years, for assessment of existing buildings, correspond to a limited-safety performance level, according to NSR-10 [8], equivalent to collapse-prevention in FEMA 440 [23]. For the design of new buildings, movements with a $10 \%$ probability of exceedance in 50 years would be taken into account, and the lateral stiffness of the structure would need to be increased to reduce drift values in compliance with the maximum allowable drift.

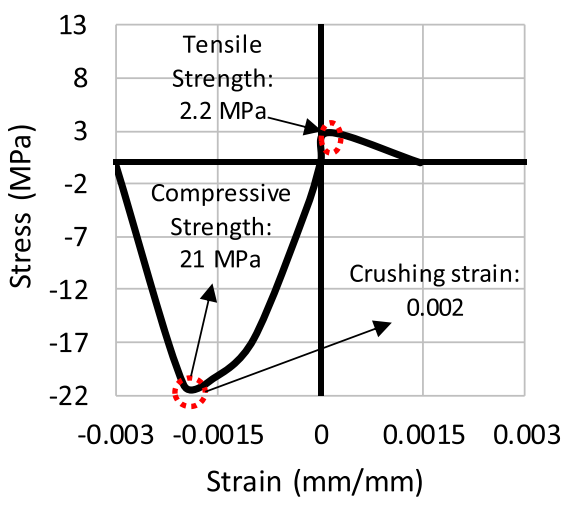

(a)

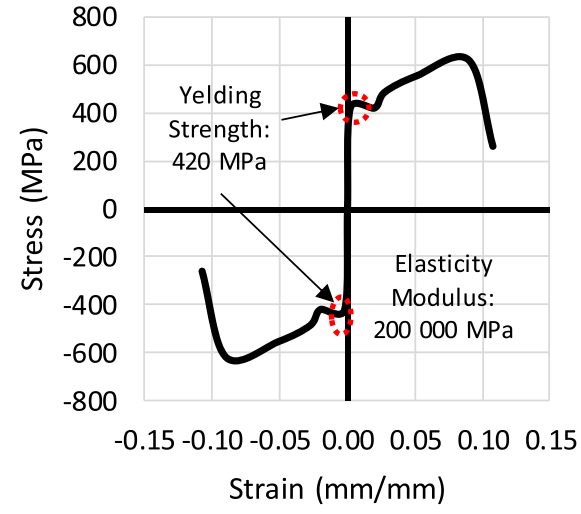

(b)

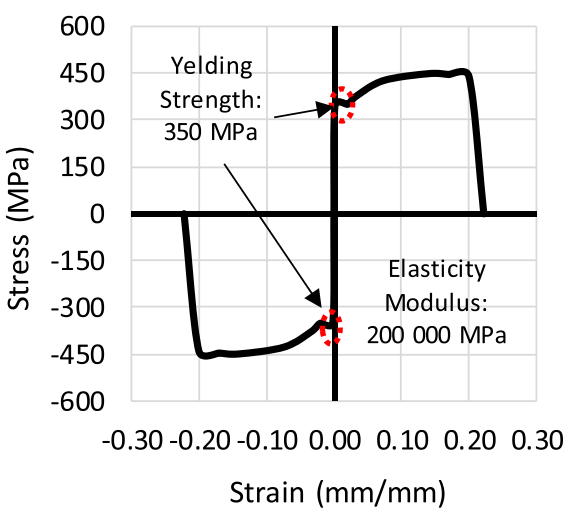

(c)

Fig. 4. Material models. Stress-strain curve (a) for concrete, (b) for steel reinforcement bars, (c) for steel angles. 


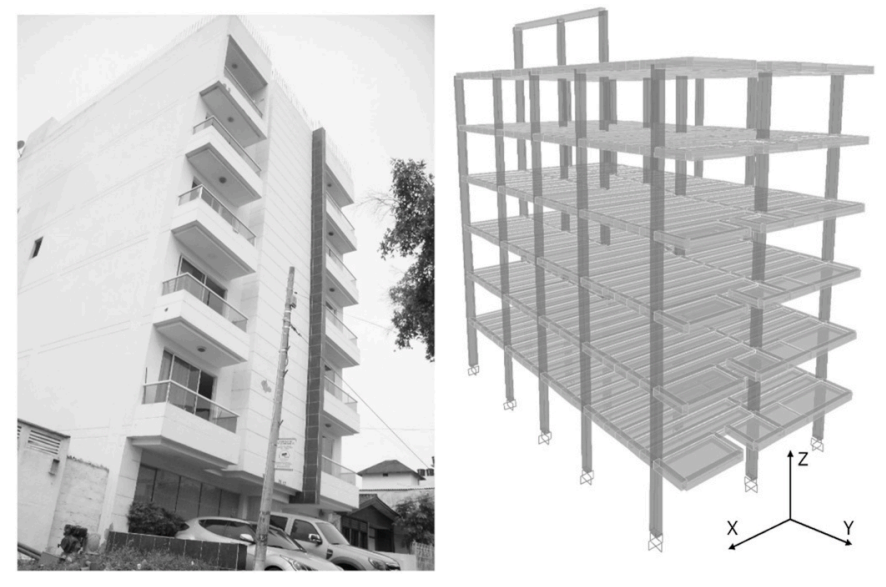

Fig. 5. Left: Existing RC building. Right: Original building Model.

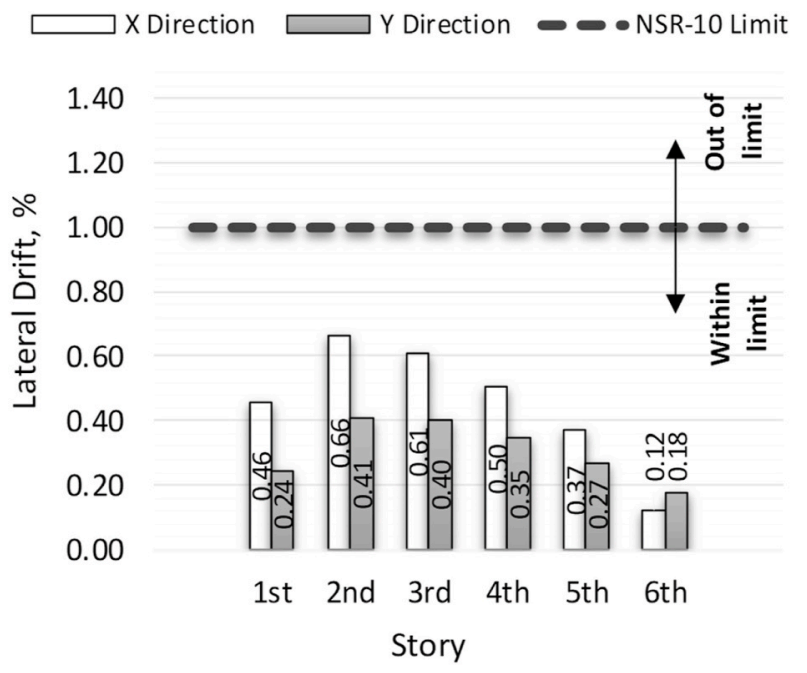

Fig. 6. Maximum lateral story drift for the existing building associated with critical load combinations along the main orthogonal directions (X and Y).

\subsubsection{Required/provided normalized reinforcement area}

The criteria for demand/capacity assessment took into account the required/provided normalized reinforcement area in structural columns. Namely, the rebar area divided by the gross area of the column sections. Fig. 7a, b, and 7c summarize the demand/capacity assessment. Three load scenarios have been considered: vertical service loads, vertical factored loads, and seismic load combinations. As PROV designates the normalized reinforcement area provided for the original columns. As LIM RC (NSR) refers to the limit for the normalized area to avoid over reinforcing of RC columns, according to NSR-10 [8], set as 4\%.

It is noted in Fig. 7a that, for vertical service loads, there are two columns (D3 and E3) requiring more than $200 \%$ of provided normalized reinforcement area on the first floor $(4.27 / 1.68$ and $3.64 / 1.68$, respectively). These two same columns are demanding $5 \%$ and $1 \%$ more reinforcement than provided on the second floor (1.76/1.68 and 1.69/ 1.68 , respectively). This same observation is available in Fig. $7 \mathrm{~b}$ and $\mathrm{c}$ for the other two load scenarios. For the most critical load combination (seismic load), nine (9) of 18 columns required retrofitting on the first floor, seven (7) on the second floor, two (2) on the third floor, and one (1) at the fourth floor. Nineteen (19) of 54 columns require an upgrade for compressive or flexural strength or both. Nevertheless, due to durability and constructional issues, 22 columns-joints need retrofitting (subsection 3.3 shows the scheme proposed): 11 on the story one, 8 on story two, 2 on story three and 1 on story four.
The considerations of demand/capacity for beams and footings are similar to those related to the columns. Beams and footings comply with the seismic code in terms of flexural strength limit. For typical beams, the critical required reinforcing area for bending is $400 \mathrm{~mm}^{2}$ according to the software outputs, and the provided reinforcing area for bending is $567 \mathrm{~mm}^{2}$. The slab and beams of the original structure behave as composite members, but conservatively, the numerical model fails in considering this composite action. The same situation for required/ provided reinforcement occurs for footings, which, the most critical footing requires $1387 \mathrm{~mm}^{2} / \mathrm{m}$, and the provided reinforcing area is $1425 \mathrm{~mm}^{2} / \mathrm{m}$ (1 \# 6 @ 200 mm).

\subsection{Modal Push-over analysis (MPA)}

The seismic assessment of a building will require consideration of its non-linear response [35]. A major challenge in performance-based earthquake engineering is to develop simple and practical methods for estimating the capacity level and seismic demand on structures considering their inelastic behavior [36]. Incremental Dynamic Analysis (IDA) has recently arisen as a comprehensive non-linear analysis method. However, it is also recognized as computationally extremely demanding for practical cases [37-39].

The push-over analysis is one of the most widely used tools for seismic assessment of structures [40]. An improved push-over method termed Modal Push-over Analysis (MPA) is selected in this study, which has shown a satisfactory degree of accuracy even in higher modes [23, 38,41 , and a trade-off between accuracy and simplicity. Subsection 4.2 shows the capacity curves for the existing and retrofitted building in the study. Section 5 presents the discussion of the stiffness, the ductility, and the seismic response modification factors based on the capacity curves.

\subsection{Steel jacketing design}

This study evaluates a steel jacketing retrofitting method to upgrade non-conforming buildings to current seismic codes. A literature review and numerical modeling performance conducted to the proposed steel jacketing details. The proposed retrofitting scheme involves steel angles covering $1 / 3$ of column length above and below of each joint (for improving flexural capacity), covering the entire length of columns (for improving axial strength), and stiffened plates for RC beams. The connection between RC columns, beams, and retrofitting elements is performed through post-installed threaded bars spaced $200 \mathrm{~mm}$ (Fig. 8).

\subsubsection{Prediction of the compressive strength of columns}

According to NSR-10 and ACI 318 [25], the axial strength design for a cross section $\left(\varnothing \mathrm{P}_{\mathrm{n} 1}\right)$ of existing columns is estimated using equation (1).

$\varnothing P_{n 1}=0.75 \varnothing\left[0.85 f_{c}^{\prime}\left(A_{g}-A_{s r}\right)+f_{y s r} A_{s r}\right]$

where $\varnothing$ is the strength reduction factor, $f_{c}$ is the compressive strength of concrete, $A_{g}$ is the gross area of the concrete section, $A_{s r}$ is the total area of longitudinal reinforcement, and $f_{y s r}$ is the rebar yield strength. Considering the material properties (Fig. 4) and dimensions of structural elements for the prototype building (Fig. 5 and Table 1), the analytical compressive strength of existing columns $\varnothing P_{n 1}$ is $1533 \mathrm{kN}$. The MRSA for the existing building helped to identify that the critical compressive load on existing columns is close to $2251 \mathrm{kN}$. Hence, the columns are overstressed. Given the overstress of existing columns due to vertical loads, one purpose of the retrofitting is to provide additional axial strength immediately to the columns, working as a composite member promptly. On the opposite, some retrofitting techniques, like FRP jacketing, work by confinement and require that columns deform axially so that the jacketing gets fully activated [19].

Compressive strength of retrofitted columns, $\varnothing P_{n 2}$, is calculated using requirements prescribed by NSR-10 and by AISC 360 [26] 


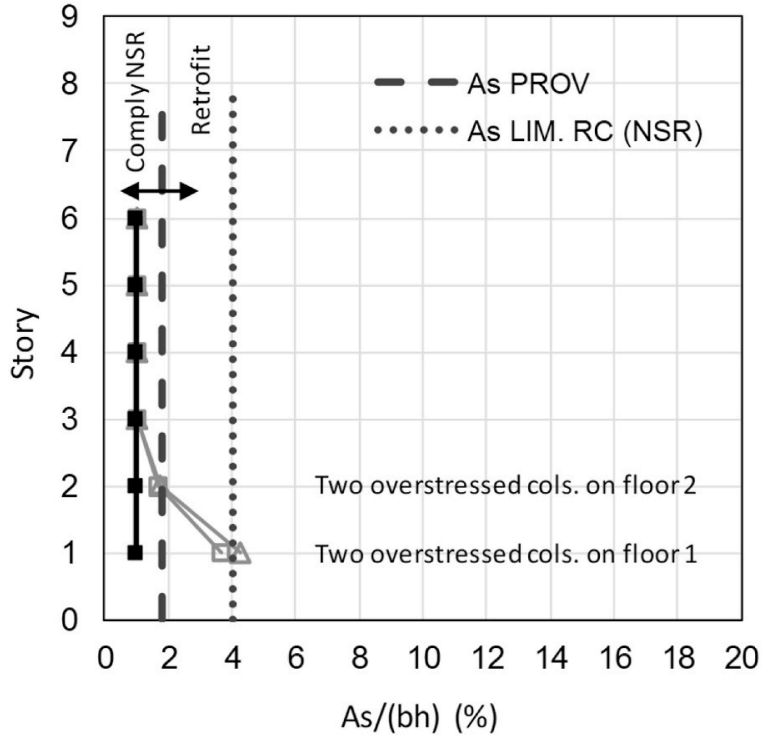

(a)

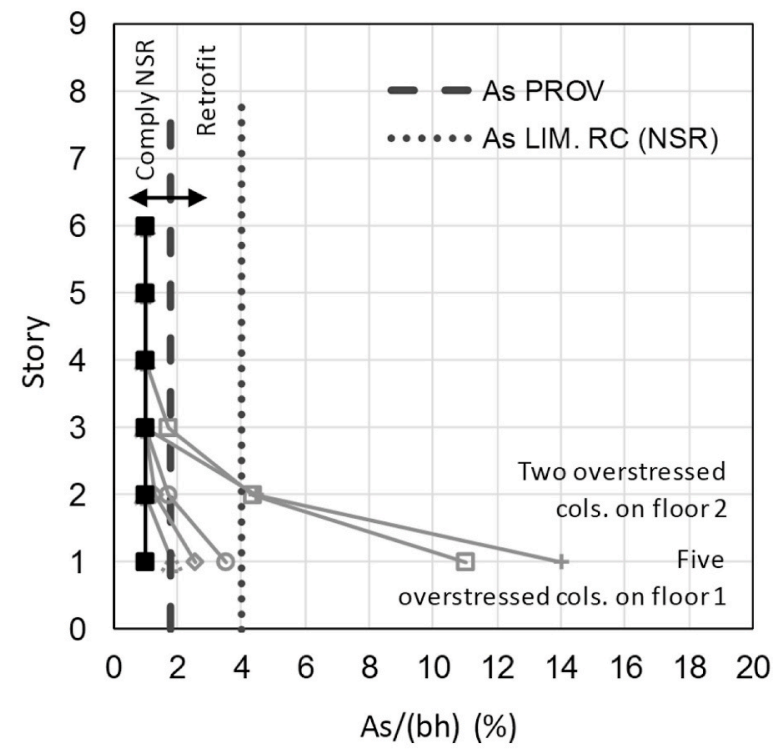

(b)

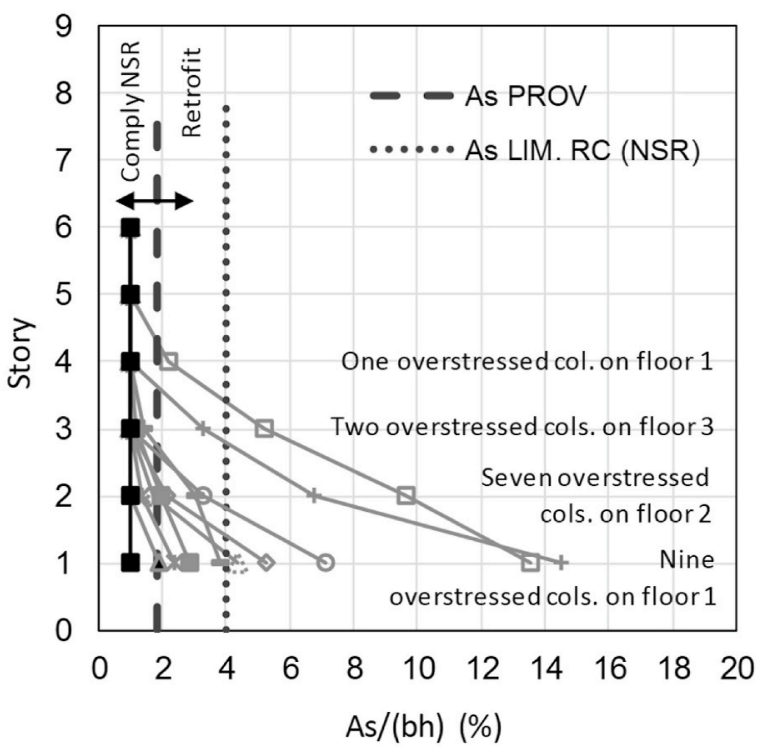

(c)

Fig. 7. Provided vs. required reinforcement area in original columns for a) vertical service loads, b) factored vertical loads, c) seismic load combinations.

specifications for composite members, equations (2)-(6).

For $P_{e} \geq 0.44 P_{n o} \Rightarrow \varnothing P_{n 2}=\varnothing P_{n o}\left[0.658^{\left(P_{n o} / P_{e}\right)}\right]$

where $P_{e}$ is the elastic critical buckling load, which is computed using equation (3).

$P_{e}=\pi^{2}\left(E I_{e f f}\right) / L_{c}^{2}$

$E I_{\text {eff }}$ expresses the stiffness of the composite section, $L_{c}$ is the effective length of the member $(K L), K$ is the effective length factor, and $L$ is the length of the member. $E I_{\text {eff }}$ is estimated with equation (4).

$E I_{e f f}=E_{s} I_{s}+E_{s} I_{s r}+C_{1} E_{c} I_{c}$

$E_{s}$ is the modulus of elasticity of steel (200 $\left.000 \mathrm{MPa}\right), E_{c}$ is the modulus of elasticity of concrete $\left(0.043 \times w_{c} \times \sqrt{f_{c}^{\prime}}\right)$, and $w_{c}$ is the weight of concrete per unit volume $\left(24 \mathrm{kN} / \mathrm{m}^{3}\right) . I_{s}$ is the moment of inertia of the steel shape about the elastic neutral axis of the composite section, $I_{s r}$ is the moment of inertia of the reinforcing bars about the elastic neutral axis of the composite section, and $I_{c}$ is the moment of inertia of the concrete section about the elastic neutral axis of the composite section. $C_{1}$ is the coefficient for calculation of effective rigidity of an encased composite compression member, computed using equation (5).

$C_{1}=0.25+3\left(\frac{A_{s}+A_{s r}}{A_{g}}\right) \leq 0.7$

The variable $P_{n o}$, used in eq. (2), is computed according to equation (6).

$P_{n o}=f_{y} A_{s}+f_{y s r} A_{s r}+0.85 f_{c}^{\prime} A_{c}$

where $f_{y s r}$ and $f_{c}^{\prime}$ were defined for eq. (1) and $f_{y}$ is the minimum yield strength of the steel section.

Accordingly, to the case under study (Fig. 5 and Table 1), the analytical compressive strength of retrofitted columns, $\varnothing P_{n 2}$, is $4411 \mathrm{kN}$. Note that the computed compressive strength of retrofitted columns is 


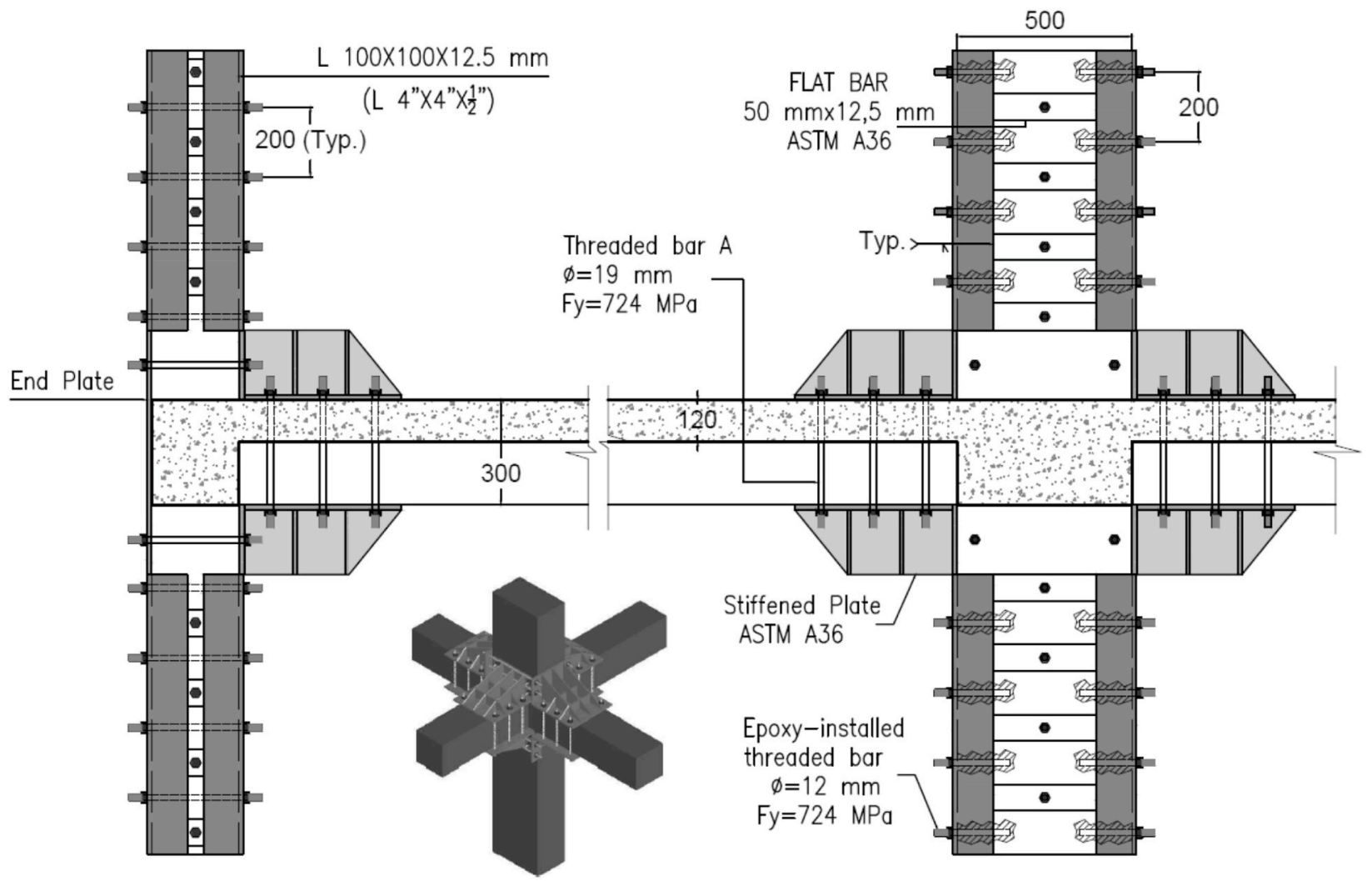

Fig. 8. Retrofitting scheme for RC columns and beam-column joints.

$187 \%$ higher than that of existing columns. This compressive strength is enough to resist the elastic strength demand of load combinations prescribed by NSR-10. Further discussion is presented in section 5 .

\subsubsection{Beams, columns, and joints flexural properties}

Section Designer, built into the software from CSi [34], facilitates the estimation of flexural properties of beams, columns, and joints. Section Designer is an integrated utility that enables the modeling and analysis of custom cross sections. This tool is useful to evaluate the flexural properties and non-linear responses of the members, including non-linear hinges. Fig. 9 summarizes the flexural properties of the retrofit scheme and original members.

The actual modeled curves show a post-peak degradation. Notice that degradation is more prominent for retrofitted columns (Fig. 9c) than for original columns (Fig. 9b), for major and minor axis, designated as MAJAXIS and MINAXIS in Fig. 9b y 9c, respectively. This degradation is associated with the fact that retrofitting generates that failure strain in concrete is reached earlier than the yield strain of steel angles is reached. Besides, notice than a strain hardening effect is shown for original columns properties (Fig. 9b) after the yielding moment is reached.

In order to compensate for post-peak degradation, idealized curves are considered, meeting ASCE 41-17 [24] to define non-linear hinges. The paper compares the numerical results for the beam to existing experimental data of a sub-assembly with a similar retrofitting scheme and beam specifications [22], in section 5 .

\section{Results of the evaluation of the retrofitted building}

Fig. 10 shows the numerical model of the retrofitted building, which comprises a 3D frame with beam-column joints properties according to the proposed retrofit scheme (Fig. 8). A MRSA and a MPA were carried out using the software.

\subsection{Modal Response Spectrum Analysis (MRSA)}

\subsubsection{Lateral inter-story drift}

Lateral inter-story drifts for the retrofitted building are computed, similar to the existing building case. Fig. 11 shows the results of the calculation. It can be noticed that the drift values are according to NSR10 requirements for all the stories. A discussion of the results is available in section 5 .

\subsubsection{Required/provided reinforcing area}

Fig. 12 summaries the results of required/provided normalized rebar area for columns, considering all the load combination cases. It is noticed in the figure that all columns require the minimum flexural reinforcing area, according to NSR-10 ( $1 \%$ of the cross-sectional area) on all floors. The Section Designer of the software considers an equivalent RC section for the retrofitted RC typical column (a composite section), with a cross section area equal to $215200 \mathrm{~mm}^{2}$. Thus, the minimum column normalized reinforcement is $1.72 \%\left(2512 \mathrm{~mm}^{2} / 1250 \mathrm{~mm}^{2}\right)$. The provided normalized reinforcement area is $1.68 \%$, as stated in Table 1 . The proposed retrofitting scheme practically eliminates the overstress on failing elements. RQRD-As-EQUV, in Fig. 12, refers to the required rebar area for the equivalent RC section. PROV-As-ORIG refers to the provided reinforcing steel area for the original cross section of the column.

\subsection{Modal Push-over analysis (MPA)}

Fig. 13 shows the deformed shape of the structure after the last step of the progressive lateral load applied to the retrofitted building along the "Y" direction. The colors of hinges represent the seismic performance levels according to AISC 360 [26], FEMA 440 [23], and ASCE 41 [24]. Although this loading step corresponds to near collapse or general instability, there are only a few hinges that go far beyond collapse-prevention performance level. 


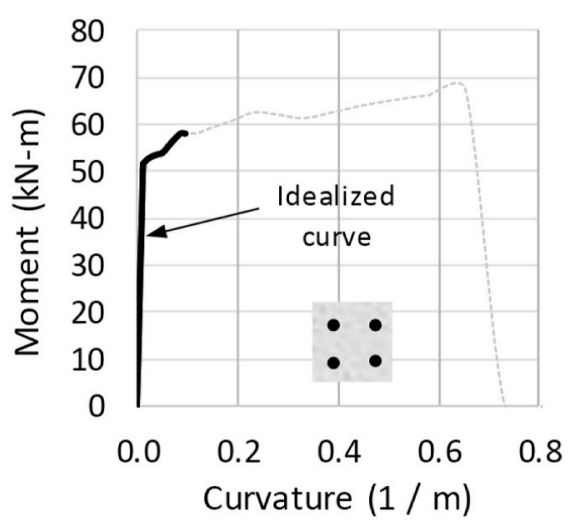

(a)

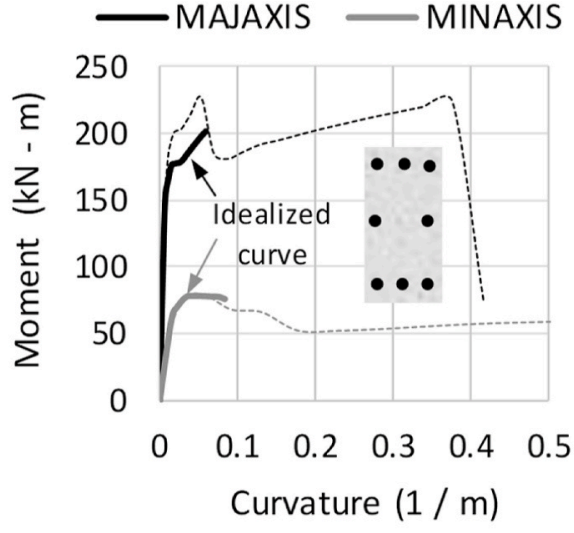

(b)

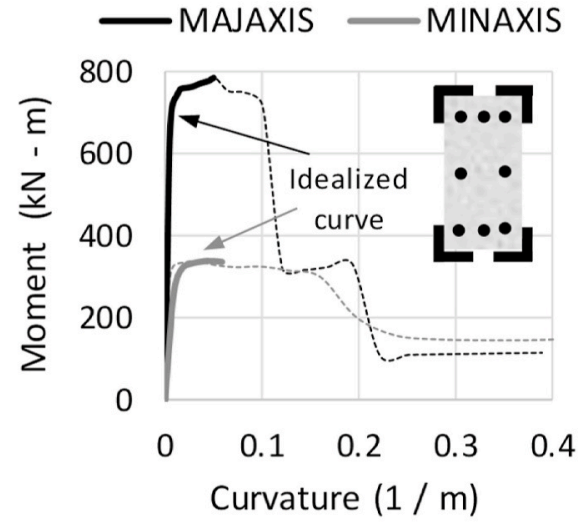

(c)

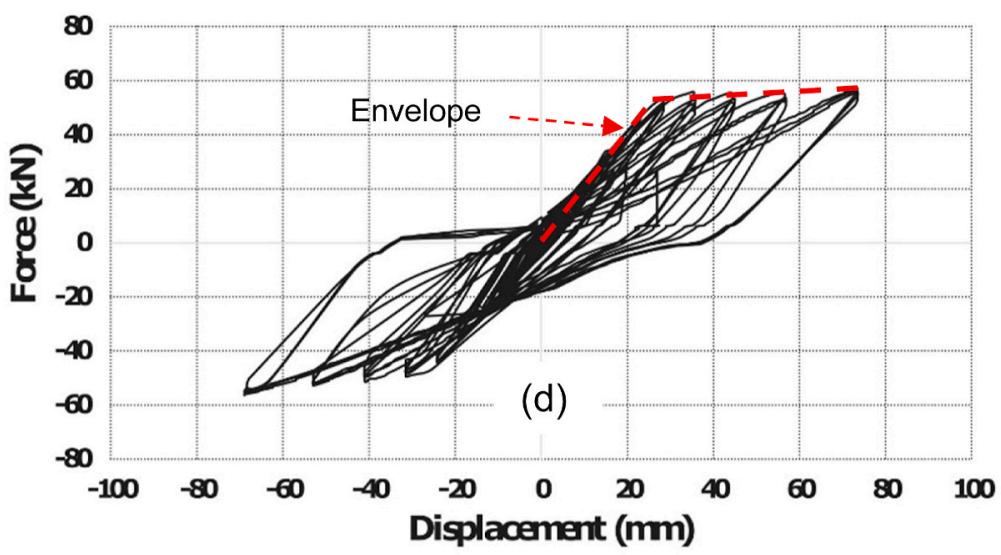

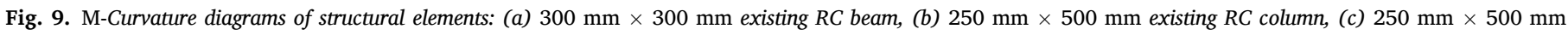
retrofitted RC column, (d) Hysteretic response of a previous study with similar retrofitted joint scheme [22].

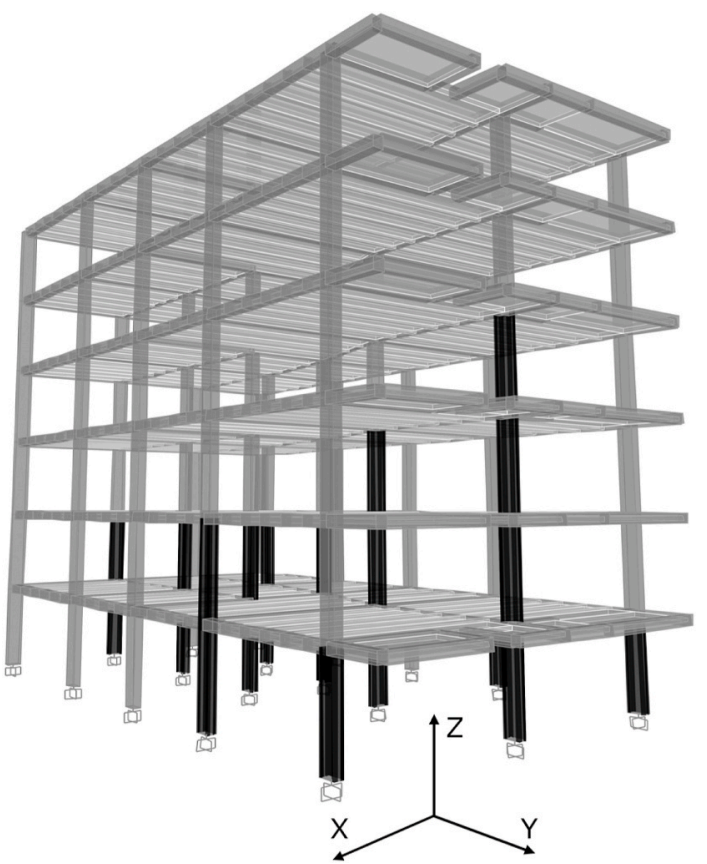

Fig. 10. Isometric view of the retrofitted building.

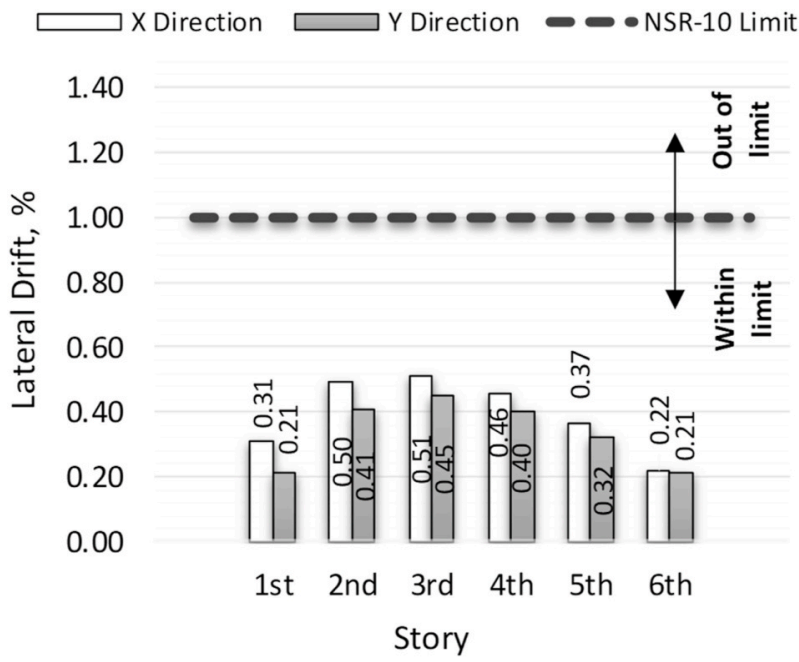

Fig. 11. Maximum lateral inter-story drift for retrofitted building under critical load combinations along the main orthogonal directions ( $\mathrm{X}$ and $\mathrm{Y}$ ).

Fig. 14 shows the capacity curve along " $\mathrm{X}$ " and " $\mathrm{Y}$ " directions for the original (designated as ORIGX and ORIGY, respectively) and for the retrofitted building (named RETRX and RETRY, respectively). The increased elastic strength of capacity curves reflects an improvement in the frame lateral strength. The target point (TP) defines the probable seismic performance of the building accordingly to site seismic movements evaluated. 


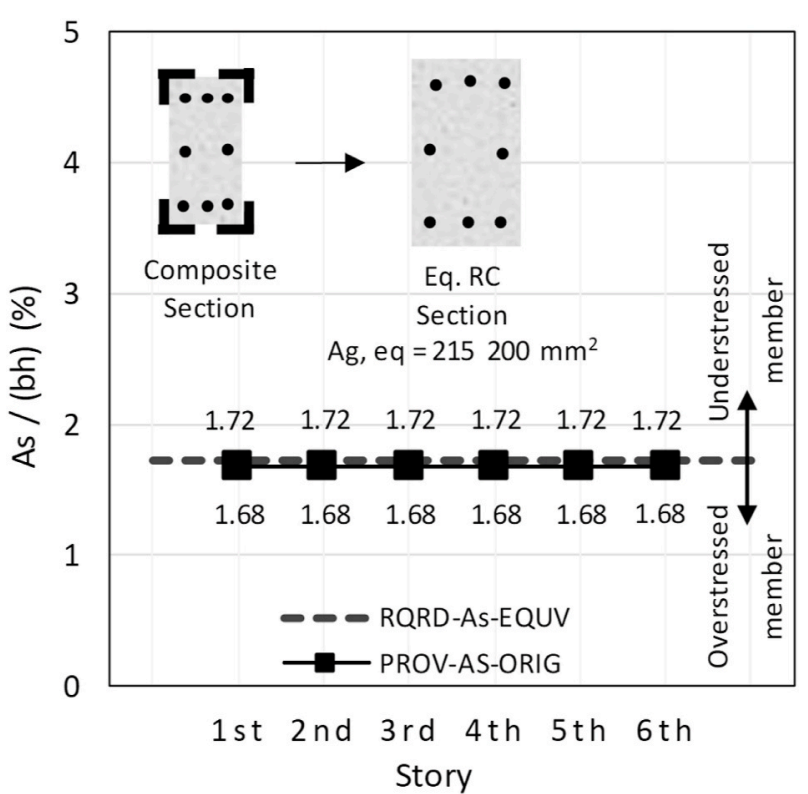

Fig. 12. Provided vs. required reinforcing area in retrofitted columns for seismic load combinations.

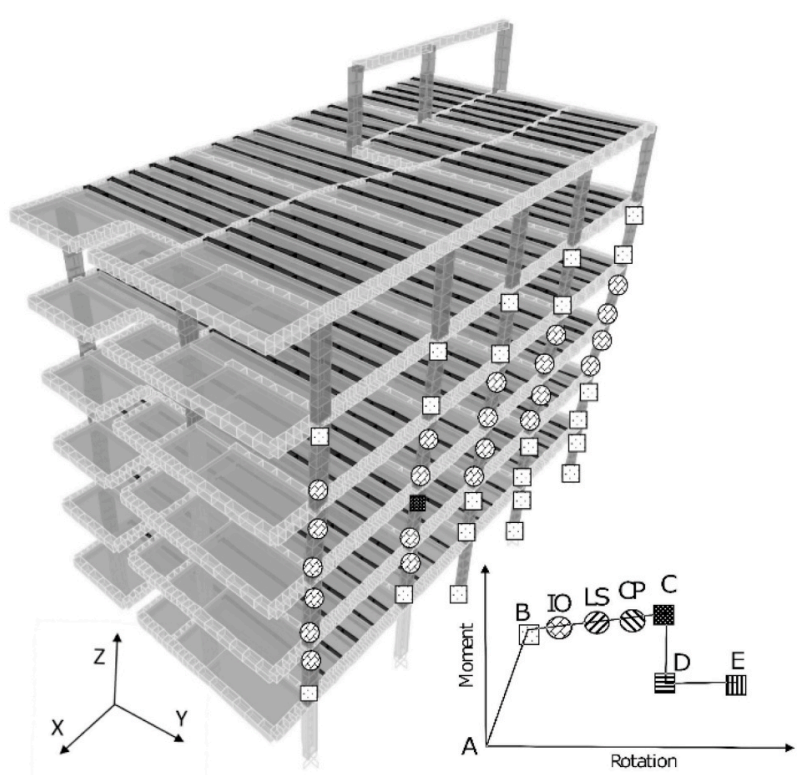

Fig. 13. Building deformation after push-over lateral loads path along "Y" direction.

The TP for the original building along " $Y$ " direction corresponds to a seismic load slightly higher than the load related to the end of the linear behavior, which corresponds to the life-safety level. Therefore, the original building shows good seismic performance along " $Y$ " direction (Fig. 14 and Table 3).

On the opposite, Fig. 14 shows that the TP for the retrofitted building along the "Y" direction corresponds to a seismic load slightly smaller than the one related to the end of linear behavior. The seismic performance of the retrofitted building along the "Y" direction corresponds to the immediate-occupancy performance level (Table 4). Further analysis, considering other seismic load scenarios, and existing material properties are presented in Section 5.

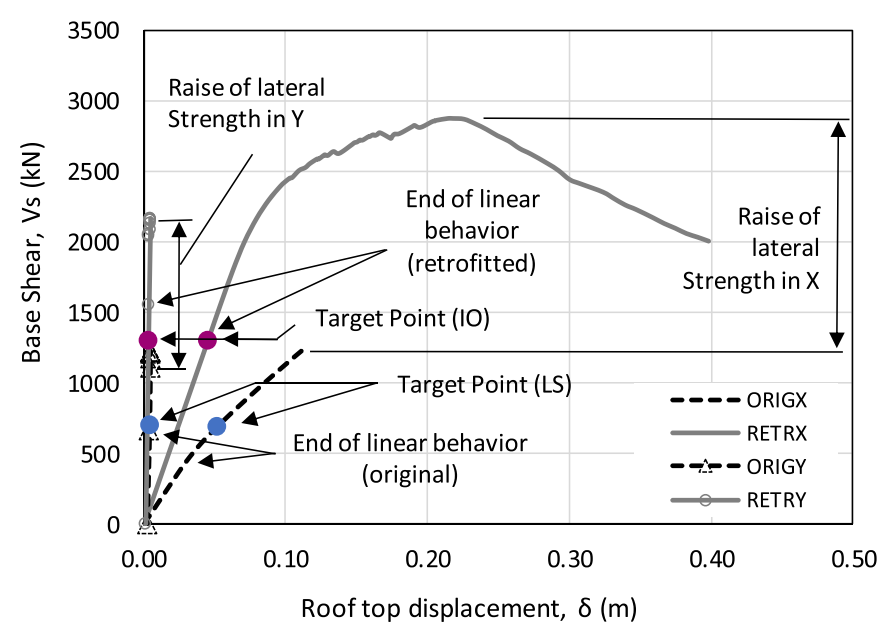

Fig. 14. Capacity curve of the existing and retrofitted structure along $X$ and $\mathrm{Y}$ directions.

Table 3

Target point data for retrofitted building according to FEMA 440.

\begin{tabular}{lll}
\hline Description & Push-over X & Push-over Y \\
\hline$V_{s}[\mathrm{kN}]$ & 1305.45 & 1305.45 \\
$D[\mathrm{~m}]$ & 0.045 & 0.00265 \\
$S_{a}[\mathrm{~g}]$ & 0.077 & 0.077 \\
$S_{d}[\mathrm{~m}]$ & 0.033 & 0.033 \\
$T_{e f f}[\mathrm{~s}]$ & 1.315 & 1.315 \\
$\beta_{\text {eff }}[\%]$ & 0.05 & 0.05 \\
$M$ & 1 & 1 \\
$V_{s}$ : base shear. $S_{a}$ : spectral acceleration. $S_{d}:$ spectral displacement. $\beta_{\text {eff: }}$ effective \\
\multicolumn{2}{r}{ damping. $T_{\text {eff: }}$ effective period. $M$ : modification factor. $D$ : rooftop displacement. } \\
\hline
\end{tabular}

\section{Discussion of results}

Firstly, the structural safety of the building is improved by the steel jacketing design proposed. The retrofitting allows the structure to comply with all the strength limit states of NSR-10 [8] seismic code. As stated in the subsection 3.1.2, for service loads, there are two columns of the original building (D3 and E3, Fig. 2) with required/provided rebar ratios equal to 2.53 and 2.16 on the first floor. This represents a high collapse hazard.

Usually, demand/capacity ratios of $0.3-0.4$ conform to all NSR-10 requirements. The demand/capacity ratio of the retrofitted columns is $0.35(1552 \mathrm{kN} / 4411 \mathrm{kN})$, as determined in subsection 3.3.1., which is more reasonable for safety purposes. High axial demand/capacity ratios diminish the ductility of columns and walls [42]. The increment of compressive column strength is $187 \%$.

The critical demand/capacity ratio due to axial loads on columns is an important criterion to select the proposed retrofitting technique in this study. The selected steel jacketing (Fig. 8) can provide composite action immediately after the retrofitting. Other techniques (e.g., FRP jacketing), which work by confinement only, need that the original columns deform to activate the additional axial strength completely [19].

FEM analysis results exhibit a gain of column flexural capacity approximately equal to $261 \%$ (Fig. 11), due to the steel jacketing. For instance, the retrofitted columns elastic-flexural-strength around the

Table 4

Building seismic performance according to FEMA 356.

\begin{tabular}{ll}
\hline Building case & FEMA 356 \\
\hline Original Building & LS: Life-safety \\
Retrofitted Building & IO: Immediate-occupancy \\
\hline
\end{tabular}


major axis is near to $552 \mathrm{kN}-\mathrm{m}$ (Fig. 11c), while the original columns elastic-flexural-strength is around $153 \mathrm{kN}-\mathrm{m}$ (Fig. 11b). Similar results are obtained around the minor axis of the column. The beams undergo a growth of $51 \%$ on the elastic-flexural-capacity. Fig. 11a displays an original beam elastic-flexural-capacity of $53 \mathrm{kN}$-m, while Fig. $11 \mathrm{~d}$ corresponds to an elastic-flexural-capacity of about $81 \mathrm{kN}-\mathrm{m}(=50 \mathrm{kN} \times$ $1.6 \mathrm{~m})$.

The maximum story drift ratios for the original building are located on the second floor, along " $\mathrm{X}$ " direction $(0.66 \%)$ and along "Y" direction (0.41\%) (Fig. 6). It can also be noticed in Fig. 6 that drifts get lower gradually from the second floor to the top, both for " $\mathrm{X}$ " and "Y" direction. The retrofitting reduces by $42 \%$ and $32 \%$ the drift ratios in " $\mathrm{X}$ " direction on the first and second floor, respectively. This reduction at the lower floors is rational if it is considered that most of the retrofitted columns (and beam-column joints) are located on 1st (11 columns) and 2nd (8 columns) floors (subsection 4.1.1). The drifts for retrofitted building follows a similar pattern than for the original building (Fig. 11). This substantial narrowing of story drifts represents a significant improvement on the seismic performance of non-structural-elements, given that structural displacements are recognized as a source of damage [9].

When comparing capacity curves in "X" and "Y" directions (Fig. 14), it can be observed that the global stiffness of the structure in the "Y" direction is higher than that in " $\mathrm{X}$ " direction, due to the redundancy along each direction. The elastic stiffness of the entire structure $(K)$ can be defined as indicated in Table 5. The retrofitting increases the stiffness around $94 \%$ in the " $\mathrm{X}$ " direction and practically does not increase the stiffness in the "Y" direction (1\% of the increment) (Table 5 summarizes the data for stiffness, extracted from Fig. 14). This slight increment of stiffness along "Y" direction reflects that the seismic behavior along "Y" remains elastic for the retrofitted building, similar to the original building.

The resisting base shear of the building increase $127 \%$ in " $\mathrm{X}$ " $\mathrm{di}-$ rection and 74\% in "Y" direction with proposed retrofitting (Fig. 14). Accordingly, the rooftop displacement for the retrofitted building is lower than for the original building, at target points.

The global inelastic behavior of the retrofitted building suffers a substantial improvement. Ductility shows a rise of $40 \%$ for " $Y$ " direction, measured with strains at the ultimate resistant base shear. A similar analysis for the " $\mathrm{X}$ " direction of the building is performed, indicating an increment of ductility of $130 \%$ in the building (Fig. 14 and Table 6).

The MPA analysis path for the original building (Fig. 14) indicates that some elements use up their ultimate-flexural-strength before the target point load. For the " $\mathrm{X}$ " direction, 227 (of 1386) plastic hinges exceed the immediate-occupancy (IO) performance level at the TP, although no hinges exceed the life-safety $(L S)$ level. 226 (of 1386) plastic hinges exceed the $I O$ performance level, and zero hinges exceed the $L S$ performance level at the TP along the "Y" direction. The retrofitting reduces the number of plastic hinges exceeding the $I O$ level. No hinges (of 1368) exceed IO performance level along " $\mathrm{X}$ " direction, and no hinges (of 1368) neither exceeds $I O$ level in "Y" under TP loads.

It can be shown in Fig. 13 that a few columns hinge before connected beams, which is not appropriate [25]. This does not mean collapse. While some columns hinge, other columns and joints are still providing stiffness and strength to the building. Research involving an

Table 5

Stiffness of retrofitted structure at linear behavior, $K$.

\begin{tabular}{|c|c|c|c|}
\hline Direction & $\begin{array}{l}\text { Original Building } \\
K(\mathrm{kN} / \mathrm{mm})\end{array}$ & $\begin{array}{l}\text { Retrofitted Building } \\
K(\mathrm{kN} / \mathrm{mm})\end{array}$ & $\begin{array}{l}\text { Increment of } K \\
(\%)\end{array}$ \\
\hline $\mathrm{X}$ & $\begin{array}{l}14.8(=433 \mathrm{kN} / \\
29.1 \mathrm{~mm})\end{array}$ & $\begin{array}{l}28.8(=1551 \mathrm{kN} / \\
53.9 \mathrm{~mm})\end{array}$ & 94 \\
\hline Y & $\begin{array}{l}855.4(=1225 \mathrm{kN} / \\
1.4 \mathrm{~mm})\end{array}$ & $\begin{array}{l}865.0(=1557 \mathrm{kN} / \\
1.8 \mathrm{~mm})\end{array}$ & 1 \\
\hline \multicolumn{4}{|c|}{$\begin{array}{l}K=V_{s y} / D \text {, where } V_{s y} \text { is the base shear at the end of linear behavior and } D \text { is the rooftop } \\
\text { displacement at the end of linear behavior. }\end{array}$} \\
\hline
\end{tabular}

Table 6

Analysis of ductility at the ultimate resistant base shear.

\begin{tabular}{|c|c|c|c|c|c|c|c|}
\hline \multirow[t]{2}{*}{ Direction } & \multicolumn{3}{|c|}{ Original Building } & \multicolumn{3}{|c|}{ Retrofitted Building } & \multirow{2}{*}{$\begin{array}{l}\text { Increment } \\
\text { of } \mu_{\mathrm{ult}} \\
\%\end{array}$} \\
\hline & $\begin{array}{l}\delta_{\text {ult }} \\
(\mathrm{mm})\end{array}$ & $\begin{array}{l}\delta_{\mathrm{y}} \\
(\mathrm{mm})\end{array}$ & $\mu_{\text {ult }}$ & $\begin{array}{l}\delta_{\text {ult }} \\
(\mathrm{mm})\end{array}$ & $\begin{array}{l}\delta_{\mathrm{y}} \\
(\mathrm{mm})\end{array}$ & $\mu_{\text {ult }}$ & \\
\hline $\mathrm{X}$ & 113.7 & 31.2 & 3.65 & 398.2 & 47.4 & 8.40 & 130 \\
\hline $\mathrm{Y}$ & 4.2 & 3.9 & 1.09 & 4.2 & 2.7 & 1.53 & 40 \\
\hline \multicolumn{8}{|c|}{$\begin{array}{l}\delta_{\text {ult }} \text { : rooftop displacement at the ultimate resistant base shear. } \delta_{\mathrm{y}} \text { : displacement at the } \\
\text { end of linear behavior. } \mu_{\mathrm{ult}} \text { : ductility at ultimate resistant base shear }\left(\mu_{\mathrm{ult}}=\delta_{\mathrm{ult}} / \delta_{\mathrm{y}}\right) \text {. }\end{array}$} \\
\hline
\end{tabular}

experimental test of a similar joint scheme [22], displays that retrofitting relocate the hinge on the beam further from the column face, as recommended by modern seismic standards to ensure a strong column-weak beam behavior [24].

One of the most valuable uses of non-linear analysis is to avoid the use of assumptions in the seismic response of the structure; for instance, the specified values of Seismic Response Modification factors $(R)$ for the elastic method of structural analysis. $R$-values can be approximately calculated, extending a line from the elastic zone of capacity curves up to demand curves, for a specific design earthquake and structure, using MPA results (eq. (7)).

$R=\frac{S_{a, p r o}}{S_{a, d}}$

$R$ : seismic response modification factor. $S_{a \text { pro }}$ : projected spectral acceleration, extending the elastic line of the capacity curve up to the demand curve ( $5 \%$ reduced because of viscous damping). $S_{a, d}$ : spectral displacement of the target point.

Table 7 shows $R$-values according to MPA results.

Despite Fig. 14 shows that the original building reaches a $L S$ performance level, it has to be considered that seven columns are not in compliment with the NSR-10 strength-limit-states just for vertical loads (Fig. 7b), which represents a limited structural safety. This reflects that, although the definition of the non-linear hinges, according to ASCE 41 [24], considers axial-flexural loads interaction, the MPA capacity curve (Fig. 14) does not display the infringement of axial strength limit states in the assessment of the performance level.

The values of seismic response modification factors, $R$, computed from the MPA curves (Table 7) show an agreement with previously selected $R$-value for MRSA, equal to two (section 2). This means that the original building has a relatively low inelastic capacity, especially in " $\mathrm{Y}$ " direction, where the building resists seismic movements lineally.

The concrete core test is the most recommended method to assess the actual compressive strength of existing RC buildings, according to some standards like ACI [25] and NSR-10 [43]. However, it is usually a controversial parameter for evaluation given that results are affected by many factors (e.g., length-diameter ratio, moisture condition, and drilling process, among others), which can easily conduct to misinterpretation [44]. A parametric analysis with different concrete columns compressive strength has been made to evaluate the influence of concrete strength on the seismic drifts, and the compressive/flexural strength.

Fig. 15a shows the lateral drifts of the original building with columns

Table 7

Seismic response modification factors, $R$, according to MPA results.

\begin{tabular}{llllll}
\hline \multirow{2}{*}{ Description } & Push-over $\mathrm{X}$ & & & \multicolumn{2}{l}{ Push-over $\mathrm{Y}$} \\
\cline { 2 - 3 } \cline { 6 - 6 } & Original & Retrofitted & & Original & Retrofitted \\
\hline $\mathrm{S}_{\mathrm{a} \text {,pro }}$ & 0.069 & 0.08 & & 0.069 & 0.079 \\
$\mathrm{~S}_{\mathrm{d}}$ & 0.04 & 0.033 & & 0.04 & 0.033 \\
$R$ & 1.73 & 2.42 & & 1.68 & 2.39 \\
\hline
\end{tabular}


considering concrete strengths of 14, 21, 28, and $35 \mathrm{MPa}$. The graphics indicate that the highest strength (35 MPa), does not provide significant changes in the drifts ratios, in comparison to the lowest strength (14 $\mathrm{MPa}$ ), especially in the highest stories. For floors 4, 5, and 6, the change in lateral drift values is short (from $0.41 \%$ to $0.33 \%$ on floor 5 ). There is a $25 \%$ change in the drifts ratios for stories 1,2 , and 3 (from $0.74 \%$ for $35 \mathrm{MPa}$ to $0.59 \%$ for $14 \mathrm{MPa}$, at floor 2).

Fig. 15b shows the lateral drift ratios of the retrofitted building varying the concrete strength of columns from 14 to 35 MPa every 7 MPa. It can be observed that the influence of concrete compressive strength on the lateral drift ratios of the retrofitted building is even lower than that for the original building. The maximum change in the drifts values is represented in story 2 , equal to $18 \%$ (from $0.44 \%$ for 35 $\mathrm{MPa}$ to $0.52 \%$ for $14 \mathrm{MPa}$ ). Drifts at Floors 1 and 6 practically do not suffer changes. The pattern displayed exhibits that retrofitting reduces lateral drifts at floors 1 and 2, where the number of retrofitted columns is 19 (of 22 in total).

Fig. 16 shows the flexural and compressive capacity of retrofitted columns, designated as RETRFLEX and RETRCOMP, respectively, and the flexural and compressive strength of original columns, named ORIGFLEX and ORIGCOMP respectively, for different column concrete compressive strength. Results demonstrate that the strength does not have any influence on the flexural capacity of original nor retrofitted columns. Notice that the lowest two lines on the graphic are horizontal.

The compressive capacity of individual columns can be increased with a gain of the concrete column axial strength for both, original RC columns by $46 \%$ ( $2245 \mathrm{kN}$ for $35 \mathrm{MPa}$ versus 1533 for $21 \mathrm{MPa}$ ) and Steel jacketing retrofitted columns by $26 \%$ (5562 $\mathrm{kN}$ for $35 \mathrm{MPa}$ versus 4411 for $21 \mathrm{MPa}$ ). Fig. 16 shows that even for $f_{c}^{\prime}=14 \mathrm{MPa}$ (a low strength concrete), the proposed retrofitting could rise the axial capacity by $225 \%$ ( $3823 \mathrm{kN}$ versus $1177 \mathrm{kN}$ ) and then, upgrade the structure to reach the specified structural safety by ACI [25] and NSR-10 [43].

The capacity curve for the retrofitted building in " $\mathrm{X}$ " direction (Fig. 14) displays a degradation post-peak with a subsequent softening. This can be explained by the significant gain of ductility and lateral resistance and by the absence of irregularities along the " $\mathrm{X}$ " direction. As the compressive strength of column-joint does not influence on the flexural capacity (Fig. 16), the material models of the steel angles and rebars (Fig. 4) govern the path of the retrofitted curve in " $\mathrm{X}$ " direction. Probably, the columns rebar yields at about $2000 \mathrm{kN}$ of base shear,

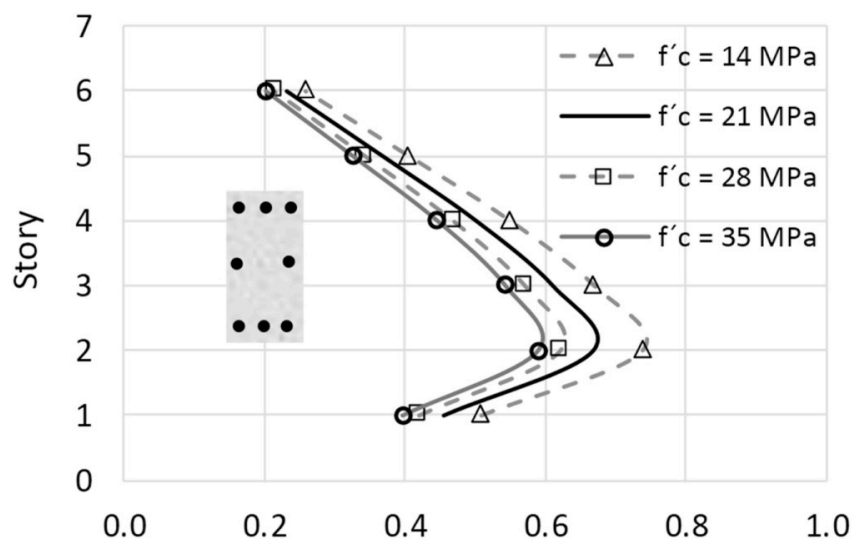

Lateral drift, \%

$$
\begin{gathered}
F_{y}=N A \cdot A_{s}=0 \mathrm{~mm}^{2}(0 \% \mathrm{Ag}) \cdot F_{\mathrm{ysr}}=420 \mathrm{MPa} . \\
A_{s r}=2100 \mathrm{~mm}^{2}\left(1.97 \% \mathrm{~A}_{\mathrm{g}}\right) . \\
E=4700\left(f_{c}^{\prime}\right)^{1 / 2}
\end{gathered}
$$

(a)

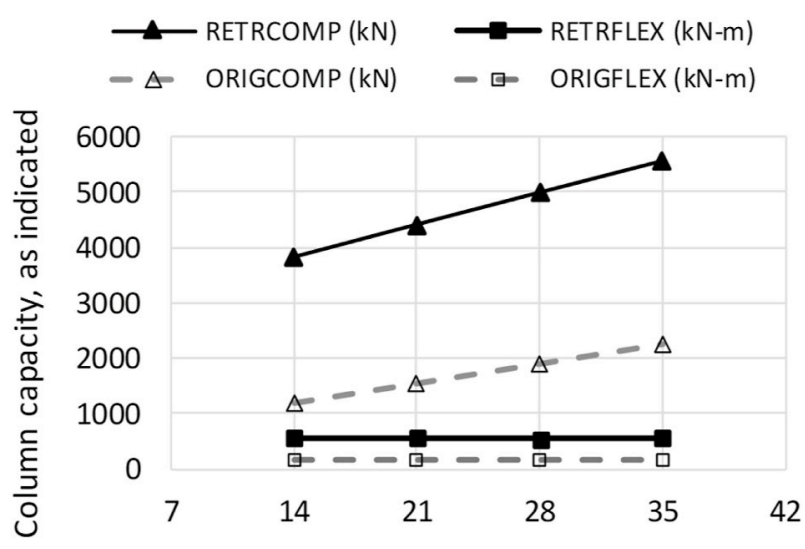

Concrete compressive strength $\left(f^{\prime}{ }_{c}\right), M P a \%$

$$
\begin{gathered}
\mathrm{F}_{\mathrm{y}}: 250 \mathrm{MPa} . \mathrm{A}_{\mathrm{s}}: 2419 \mathrm{~mm} 2\left(1.93 \% \mathrm{~A}_{\mathrm{g}}\right) . \\
\mathrm{F}_{\mathrm{ysr}}=420 \mathrm{MPa} . \\
\mathrm{A}_{\mathrm{sr}}=2100 \mathrm{~mm} 2\left(1.97 \% \mathrm{~A}_{\mathrm{g}}\right)
\end{gathered}
$$

Fig. 16. Columns capacity for different concrete compressive strength.

causing an initial stiffness degradation, thus going far beyond their elastic limit until the peak of the base shear, near to $2800 \mathrm{kN}$. Then, the steel angles get into plastic deformations, and the retrofitted building shows another stiffness degradation (Fig. 14).

The original building in the " $\mathrm{X}$ " direction shows a shorter inelastic ability than the retrofitted building in the same direction "X" (Fig. 14). Inelastic strains of rebars start at a base shear near to $500 \mathrm{kN}$, causing the stiffness degradation up to the peak of the resisting base shear of about $1300 \mathrm{kN}$. However, in general, capacity curves in direction "X" show better inelastic capacity than curves in "Y" direction (Fig. 14). The reasons are that there are fewer columns in frames along " $\mathrm{Y}$ " direction than in frames along " $\mathrm{X}$ " direction, 14 of 18 columns are oriented with their minor axis in "Y" direction (Fig. 2) and the irregularity caused by the reduction on the number of columns in axis D and E (Fig. 2). As redundancy of frames depends on the number of columns, and ductility depends on redundancy, reasonably, the capacity curves in "Y" direction, shows a non-ductile behavior for original and retrofitted building

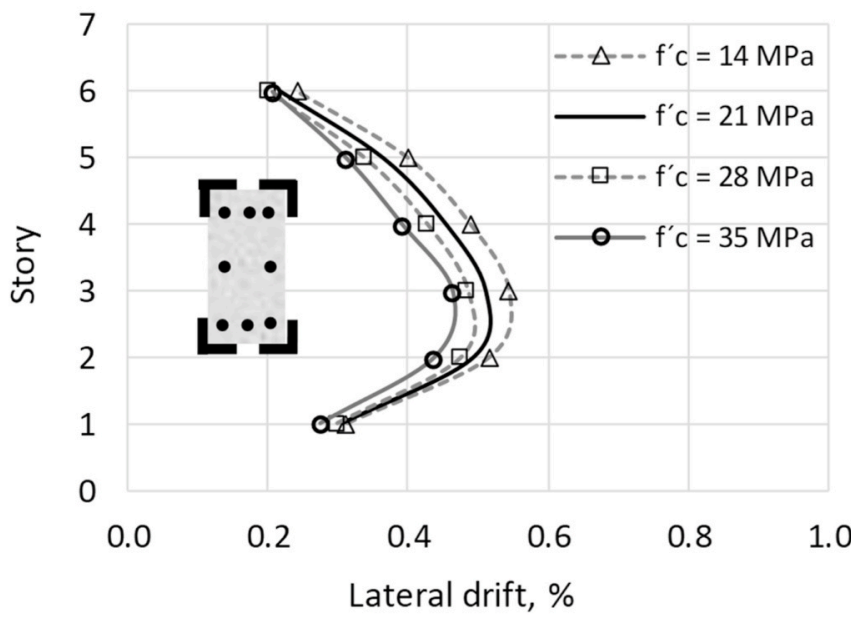

$$
\begin{gathered}
F_{y}=250 \mathrm{MPa} \cdot A_{s}=2419 \mathrm{~mm}^{2}\left(1.93 \% \mathrm{~A}_{\mathrm{g}}\right) . \\
\mathrm{F}_{\mathrm{ysr}}=420 \mathrm{MPa} . \\
\mathrm{A}_{\mathrm{sr}}=2100 \mathrm{~mm}^{2}\left(1.97 \% \mathrm{~A}_{\mathrm{g}}\right) \cdot \mathrm{E}=4700\left(\mathrm{f}_{\mathrm{c}}{ }^{\prime}\right)^{1 / 2}
\end{gathered}
$$

(b)

Fig. 15. Story drifts for different concrete compressive strength (a) Original building (b) Retrofitted building. 
(elastic behavior).

The influence of the compressive strength of existing RC building on the capacity curves has been estimated through a parametric analysis (Fig. 17a and 17b) varying f' from $14 \mathrm{MPa}$ to $35 \mathrm{MPa}$. The capacity curves of the original building are designated as ORIGX-14MPa to ORIGX-35MPa for the " $\mathrm{X}$ " direction and are designated as ORIGY$14 \mathrm{MPa}$ to ORIGY-35MPa for the "Y" direction. The maximum peaks of the capacity curves in the " $\mathrm{X}$ " direction are proportional to the compressive strength of RC elements, excepting for ORIGX-28MPa (Fig. 17a). Given that the axial strength does not affect the flexural capacity of elements, the gain of resisting base shear of the building is due to the P-M interaction and the increment on the Young Modulus of concrete. Then, for original columns, the limit to the raise on the base shear occurs for $28 \mathrm{MPa}$. It is probable that for higher values of $\mathrm{f}^{\prime}$, the mechanism starts to be influenced more by bending than by compression.

The capacity curves of the retrofitted building are designated as RETRX-14MPa to RETRX-35MPa for the " $\mathrm{X}$ " direction and are designated as RETRY-14MPa to RETRY-35MPa for the "Y" direction. The maximum peak of the capacity curves for the retrofitted building in the " $\mathrm{X}$ " direction, rounds $2881 \mathrm{kN}$ for RETRX-21MPa, and $3243 \mathrm{kN}$ (Fig. 17a) for RETRX-35MPa. This represents an increment of $13 \%$. In the case of the original building, an increment of $30 \%$ is given by a change in the resisting base shear from $1297 \mathrm{kN}$, to $1688 \mathrm{kN}$, for $21 \mathrm{MPa}$ and $35 \mathrm{MPa}$, respectively.

The capacity curves RETRX-14MPa to RETRX-35MPa (Fig. 17a) reflect that the ultimate rooftop displacement not only depends on the compressive strength of concrete because there is not a constant trend. The ultimate rooftop displacement for the retrofitted building depends on the interaction between the compressive resistance of concrete and the strength of the steel of the retrofitting scheme (Fig. 8). However, it shall be noticed that the degradation post-peak follows the same course for RETRX-14MPa to RETRX-35MPa.

The influence of different compressive strength of concrete on the Ultimate rooftop displacements, elastic stiffness, and maximum resisting base shear in "Y" direction is not perceptible if the same axis scale as for the " $\mathrm{X}$ " direction is used. Capacity curves need to be zoomed to notice any change (Fig. 17b).

Different values of concrete compressive strength practically do not

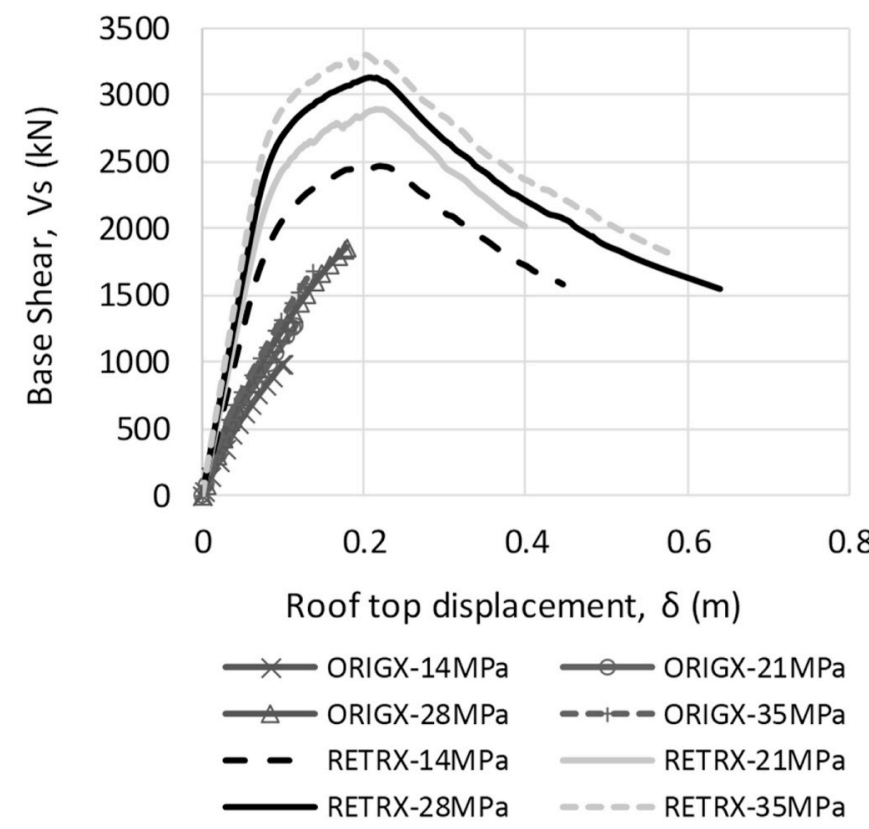

(a) affect the capacity curves along the "Y" direction (Fig. 17b). The inelastic behavior in the "Y" direction is not considerable. Rebars and steel angles do not yield when the failure mechanism appears. The failure is controlled by the geometry of the building structure. There is a less number of columns for frames along " $Y$ " direction compared with the number for frames along " $\mathrm{X}$ " direction, 78\% (14 of 18) of the columns are oriented with their minor axis in "Y" direction (Fig. 2) and the irregularity of axis D and E (Fig. 2).

The capacity curves in the "Y" direction, shows a non-ductile behavior for all the cases, ORIGY-14MPa to ORIGY-35MPa and RETRY-14MPa to RETRY-35MPa. Although the curve for the original building shows an ascendant tendency, its structural behavior remains elastic (Fig. 17b). The capacity curves for retrofitted building in "Y" direction (Fig. 17b) show an increment of $22 \%$ in the maximum peak, represented by $2131 \mathrm{kN}$ for RETRY-21MPa, and $2530 \mathrm{kN}$ for RETRY35MPa (Fig. 17b). Besides, the rooftop displacements for the retrofitted building are similar for different concrete strengths. For the original building, displacements increase $5 \%$, inversely to concrete strengths.

The influence of different seismic load scenarios on the capacity curves is analyzed. Seismic movements with ground acceleration $A_{a}$ of $0.10 \mathrm{~g}$ are designated as RETRAa $=0.10$. Movements with $A_{a}$ of $0.20 \mathrm{~g}$ are designated as RETRAa $=0.20$, and seismic loads with $A_{a}$ of $0.05 \mathrm{~g}$ are called RETRAa $=0.05$ (Fig. 18a and b).

RETRX in Fig. 18a shows that the retrofitted building can perform at $L S$ level for all the load scenarios considered, along the "X" direction. On the opposite, although the demand spectrums are reduced taking into account the effective period and damping of the structure as per FEMA 440 [23], it shall be noticed that in practical terms, the original building, designated as ORIGX is not able to sustain the seismic movements with $A_{a}$ of $0.10 \mathrm{~g}$ nor $0.20 \mathrm{~g}$ (Fig. 18a). RETRY and ORIGY displays that the elastic behavior of both, retrofitted and original building, limit the ability to withstand earthquakes with $A_{a}$ of $0.10 \mathrm{~g}$ and $0.20 \mathrm{~g}$ (Fig. 18b).

$A_{a}$ equal to 0.05 and $0.10 \mathrm{~g}$ corresponds to a low-seismic-hazard zone, and $A_{a}$ of 0.20 corresponds to a moderate-seismic-hazard zone, according to NSR-10 [43]. Given the previous discussion, it can be stated that retrofitting allows the building to perform adequately for seismic movements of moderate-seismic-hazard zones in the " $\mathrm{X}$ " direction. Nonetheless, the geometry irregularities limit the safe performance

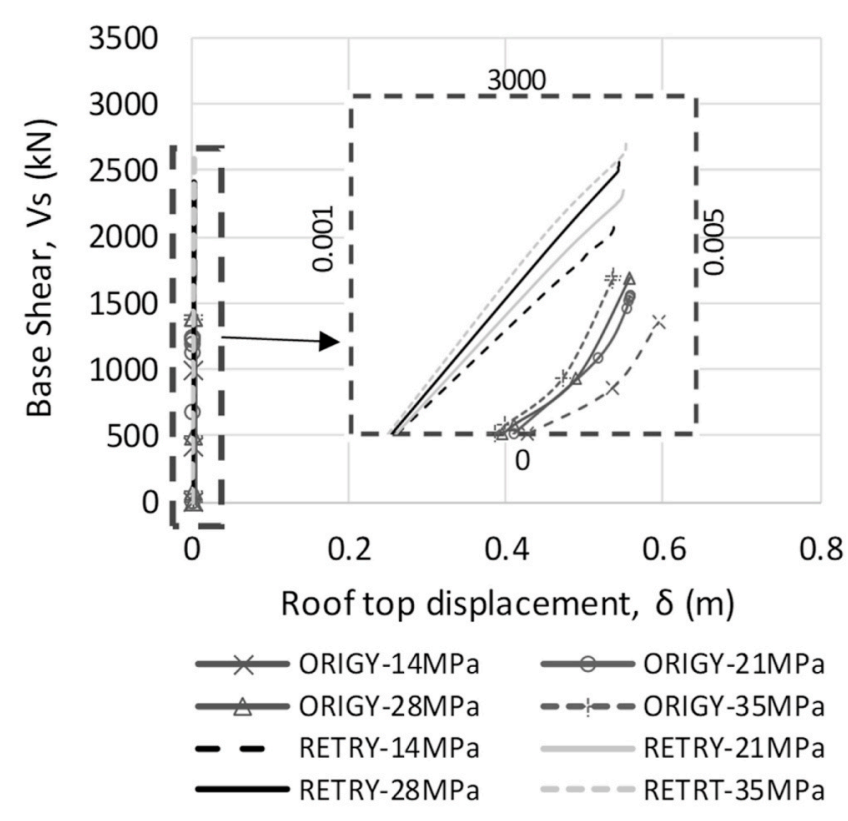

(b)

Fig. 17. Capacity curves for different concrete compressive strength a) "X" direction, b) "Y" direction. 

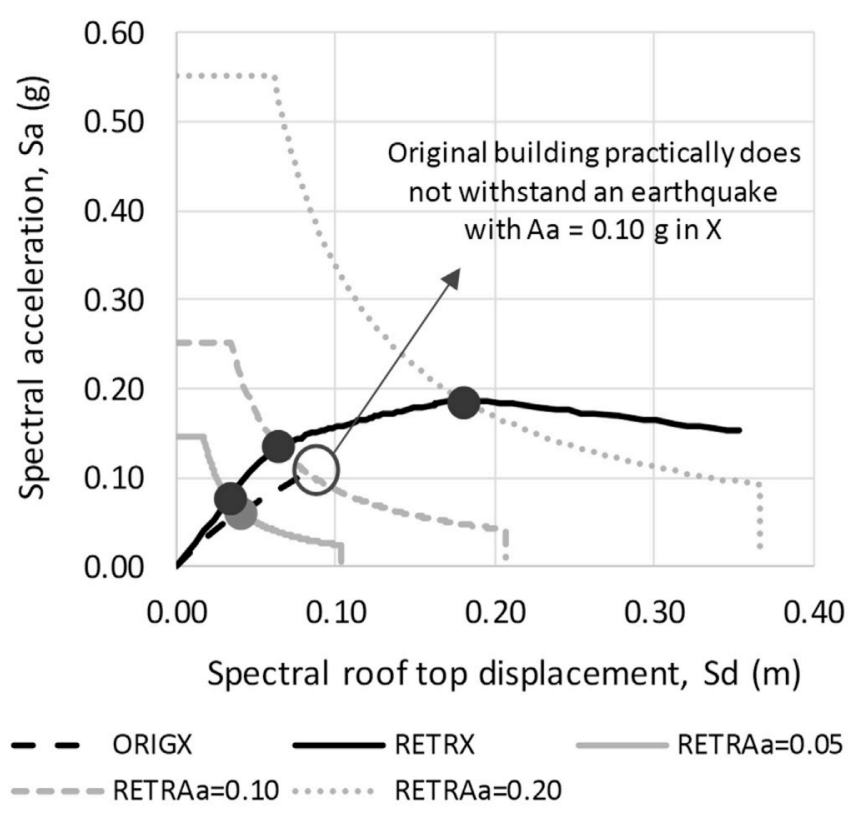

(a)
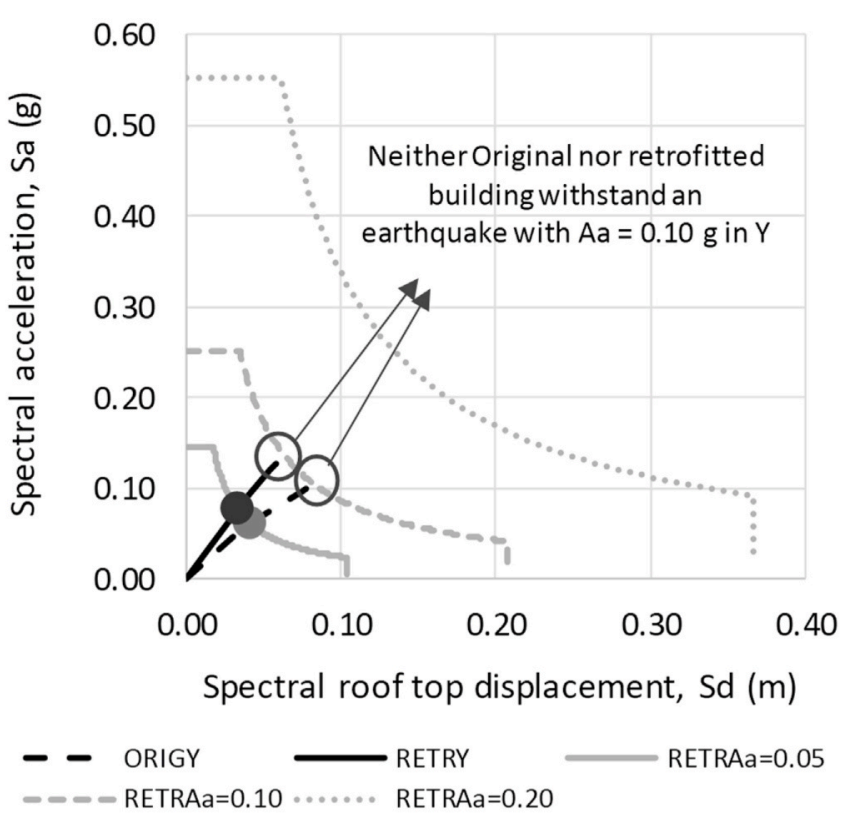

(b)

Fig. 18. Capacity spectrums for different seismic movements: a) "X" direction, b) "Y" direction.

along the "Y" direction, at low-seismic-hazard zones.

\section{Conclusions}

The results of this study demonstrated that the proposed retrofitting scheme enhances the individual axial and flexural column strength by $187 \%$ and $261 \%$, respectively, and that the flexural resistance of individual columns is not influenced by the concrete compressive strength.

The steel jacketing raises the lateral strength of the building due to the stiffening of the joint of frames, by $127 \%$ along the " $X$ " direction and $74 \%$ along the " $Y$ " direction. An increment in the concrete strength from $21 \mathrm{MPa}$ to $35 \mathrm{MPa}$, lead to an increment of $20 \%$ in the lateral strength of the retrofitted and the original building; however, the influence in the seismic drifts is not so representative, as the highest reduction in the story drift values is of $0.1 \%$.

The non-linear behavior of the retrofitted building suffers an important improvement in comparison with the original building. Ductility increased $40 \%$ for the " $Y$ " direction and $130 \%$ for the " $\mathrm{X}$ " direction. Concrete compressive strength has no substantial influence on ductility, nor the failure mechanism.

The geometrical irregularities along the "Y" direction of the prototype building limit the seismic performance of the structure at lowseismic-hazard zones. The retrofitting allows the global structure to ascend from life-safety to immediate-occupancy performance.

\section{Declaration of Competing Interest}

The authors declare that they have no known competing for financial interests or personal relationships that could have appeared to influence the work reported in this paper.

\section{Acknowledgments}

Authors thank the work of two students, Álvaro Hernández, and Roberto Babilonia, during their graduate thesis under the direction of the corresponding author. The help of Sebastian Pacheco during the revision process, as a research assistant, is especially valued. Besides, the comments from Oscar Coronado are appreciated, which have enhanced the quality of the figures, and the paper in general.
This research did not receive any specific grant from funding agencies in the public, commercial, or not-for-profit sectors. The third author acknowledges to Universidad Militar Nueva Granada in Bogotá, Colombia, for financing his research activities.

\section{Appendix A. Supplementary data}

Supplementary data to this article can be found online at https://doi. org/10.1016/j.jobe.2020.101510.

\section{References}

[1] H. Abou-Elfath, M. Ramadan, F. Omar Alkanai, Upgrading the seismic capacity of existing RC buildings using buckling restrained braces, Alexandria Engineering Journal 56 (2017) 251-262, https://doi.org/10.1016/j.aej.2016.11.018.

[2] J.P. Moehle, State of Research on Seismic Retrofit of Concrete Building Structures in the US, US-Japan Symposium and Workshop on Seismic Retrofit of Concrete Structures, 2000, p. 16.

[3] P. Ricci, F. De Luca, G.M. Verderame, 6th April 2009 L'Aquila earthquake, Italy: reinforced concrete building performance, Bull. Earthq. Eng. 9 (2011) 285-305, https://doi.org/10.1007/s10518-010-9204-8.

[4] H. Sezen, A.S. Whittaker, K.J. Elwood, K.M. Mosalam, Performance of Reinforced Concrete Buildings during the August 17, 1999 Kocaeli, Turkey Earthquake, and Seismic Design and Construction Practise in Turkey, Eng. Struct. vol. 25 (2003) 103-114, https://doi.org/10.1016/S0141-0296(02)00121-9.

[5] V. Singh Rawat, Increasing the Strength of Existing Building Using Steel Jacketing in Seismic Zone. https://doi.org/10.14445/23488352/IJCE-V4I12P102, 2017.

[6] R.S. Aboutaha, M. Engelhardt, J.O. Jirsa, M.E. Kreger, Rehabilitation of Shear Critical Concrete Columns by Use of Rectangular Steel Jackets, 1999.

[7] H. Fukuyama, S. Sugano, Japanese seismic rehabilitation of concrete buildings after the Hyogoken-Nanbu Earthquake, Cement Concr. Compos. 22 (2000) 59-79, https://doi.org/10.1016/S0958-9465(99)00042-6.

[8] AIS, Reglamento colombiano de construcción sismo resistente, NSR-10, Asociación de ingeniería sísmica, Bogotá, Colombia, 2010.

[9] F.E.M.A.74 Fema, Reducing the Risks of Nonstructural Earthquake Damage, A Practical Guide, 1994. https://www.fema.gov/media-library-data/201307261721-25045-8384/fema_74_3rd_ed.pdf.

[10] S. Pampanin, U. Akguzel, G. Attanasi, Seismic upgrading of 3-D exterior R.C. Beam Column Joints Subjected to Bi-directional Cyclic Loading Using GFRP Composites, 2019.

[11] J.M. Castro, M. Araújo, M. D’Aniello, R. Landolfo, Strengthening of RC buildings with steel elements, in: A. Costa, A. Arêde, H. Varum (Eds.), Strengthening and Retrofitting of Existing Structures, Springer Singapore, Singapore, 2018, pp. 139-162, https://doi.org/10.1007/978-981-10-5858-5_6.

[12] J. Melo, D.A. Pohoryles, T. Rossetto, H. Varum, Performance Comparison of RC Retrofitted Interior Beam-Column Joints with CFRP and Steel Plates, 2017. 
[13] Georgios Tsionis, Fabio Taucer, Roberta Apostolska, Effectiveness of Techniques for Seismic Strengthening of RC Frame Buildings, 2015, pp. 1-8.

[14] F. Nateghi-A, Seismic strengthening of eightstorey RC apartment building using steel braces, Eng. Struct. 17 (1995) 455-461, https://doi.org/10.1016/0141-0296 (95)00071-E.

[15] R. Azarm, M.R. Maheri, A. Torabi, Retrofitting RC joints using flange-bonded FRP sheets, Iranian Journal of Science and Technology, Transactions of Civil Engineering 41 (2017) 27-35, https://doi.org/10.1007/s40996-016-0028-x.

[16] A. Costa, A. Arêde, H. Varum, Strengthening and Retrofitting of Existing Structures, Springer Singapore, 2017. https://books.google.com.co/books?id=Ge8 5DWAAQBAJ.

[17] S.A. Hadigheh, M. Maheri, S. Mahini, Performance of Weak-Beam, Strong-Column RC Frames Strengthened at the Joints by FRP, 2013.

[18] C.Y. Osman Kaya Azadeh Parvin, Selçuk Altay, Retrofitting of reinforced concrete beam-column joints by composites-Part I: experimental study, Structural Journal 116 (2019), https://doi.org/10.14359/51706922.

[19] A. Ilki, E. Tore, C. Demir, M. Comert, Seismic performance of a full-scale FRP retrofitted sub-standard RC building, in: K. Pitilakis (Ed.), Recent Advances in Earthquake Engineering in Europe: 16th European Conference on Earthquake Engineering-Thessaloniki 2018, Springer International Publishing, Cham, 2018, pp. 519-544, https://doi.org/10.1007/978-3-319-75741-4_22.

[20] U. Akguzel, S. Pampanin, Effect of Axial Load Variation on the Retrofit of Exterior Reinforced Concrete Beam-Column Joints, 2019.

[21] N. Islam, M.M. Hoque, Strengthening of reinforced concrete columns by steel jacketing: a state of review, Asian Trans. Eng. 5 (2015).

[22] A. Torabi, M.R. Maheri, Seismic repair and retrofit of RC beam-column joints using stiffened steel plates, Iranian Journal of Science and Technology, Transactions of Civil Engineering 41 (2017) 13-26, https://doi.org/10.1007/s40996-016-0027-y.

[23] FEMA 440 (ATC-55), Improvement of Nonlinear Static Seismic Analysis Procedures, 2005

[24] ASCE/SEI 41-17, Seismic Evaluation and Retrofit of Existing Buildings, 2017, https://doi.org/10.1061/9780784414859.

[25] ACI 318, Building Code Requirements for Structural Concrete and Commentary, 2014 accessed, https://www.concrete.org/store/productdetail.aspx?ItemID=318 $4 \&$ Format $=$ PROTECTED_PDF\&Language $=$ English \&Units=US_Units. (Accessed 14 February 2019).

[26] AISC 360, Specification for Structural Steel Buildings, 2016 accessed, https://www.aisc. org/Specification-for-Structural-Steel-Buildings-ANSIAISC-360-16-1\#.XG XrjlxKjIU. (Accessed 14 February 2019).

[27] G.G. Meyerhof, The ultimate bearing capacity of foundations, Geotechnique 2 (1951) 301-332, https://doi.org/10.1680/geot.1951.2.4.301.

[28] K. Terzaghi, R.B. Peck, G. Mesri, Soil Mechanics in Engineering Practice, John Wiley \& Sons, 1996.
[29] B. Benmokrane, B. Zhang, A. Chennouf, Tensile properties and pullout behaviour of AFRP and CFRP rods for grouted anchor applications, Construct. Build. Mater. 14 (2000) 157-170, https://doi.org/10.1016/S0950-0618(00)00017-9.

[30] J. Mander, M. Priestley, Park, Theoretical stress-strain model for confined concrete, American Society of Civil Engineers 114 (1988) 1804-1826.

[31] J.E. Martínez-Rueda, A.S. Elnashai, Confined concrete model under cyclic load, Mater. Struct. 30 (1997) 139-147, https://doi.org/10.1007/BF02486385.

[32] S. Elkholy, B.E. Ariss, Enhanced external progressive collapse mitigation scheme for RC structures, Int. J. Struct. Eng. 7 (2016) 63, https://doi.org/10.1504/ IJSTRUCTE. 2016.073679.

[33] A. Charney Finley, Seismic loads: guide to the seismic load, Provisions of ASCE 7-10 (2015), https://doi.org/10.1061/9780784413524.

[34] Computer and Structures Inc, Concrete Frame Design Manual ACI 318-11 for SAP 2000, 2016 accessed, http://docs.csiamerica.com/manuals/sap2000/Design /CFD-ACI-318-11.pdf. (Accessed 9 February 2019).

[35] D. Saborio-Romano, G.J. O’Reilly, D.P. Welch, L. Landi, Simplified pushover analysis of moment resisting frame structures AU - sullivan, Timothy J., Journal of Earthquake Engineering (2018) 1-28, https://doi.org/10.1080/ 13632469.2018.1528911.

[36] R. Sheth, J. Prajapati, D. Soni, Comparative study nonlinear static pushover analysis and displacement based adaptive pushover analysis method, Int. J. Struct. Eng. 9 (2018) 81-90, https://doi.org/10.1504/IJSTRUCTE.2018.090753.

[37] Azarbakht Alireza, Dolšek Matjaž, Progressive incremental dynamic analysis for first-mode dominated structures, J. Struct. Eng. 137 (2011) 445-455, https://doi. org/10.1061/(ASCE)ST.1943-541X.0000282.

[38] S.W. Han, A.K. Chopra, Approximate incremental dynamic analysis using the modal pushover analysis procedure, Earthq. Eng. Struct. Dynam. 35 (2006) 1853-1873, https://doi.org/10.1002/eqe.605.

[39] D. Vamvatsikos, Performing incremental dynamic analysis in parallel, Comput Struct. 89 (2011) 170-180, https://doi.org/10.1016/j.compstruc.2010.08.014.

[40] G.P. Cimellaro, T. Giovine, D. Lopez-Garcia, Bidirectional pushover analysis of irregular structures, J. Struct. Eng. 140 (2014), 04014059, https://doi.org/ 10.1061/(ASCE)ST.1943-541X.0001032.

[41] Q.-S. "Kent" Yu, R. Pugliesi, M. Allen, C. Bischoff, Assessment of modal pushover analysis procedure and its application to seismic evaluation of existing buildings. 13th World Conference on Earthquake Engineering, Canadá, Vancouver, 2004. Paper No. 1104.

[42] T.Y.P. Yuen, J.S. Kuang, D.Y.B. Ho, Ductility design of RC columns. Part 1: consideration of axial compression ratio, Trans. Hong Kong Inst. Eng. 23 (2016) 230-244, https://doi.org/10.1080/1023697X.2016.1232179.

[43] AIS, NSR-10, Reglamento colombiano de Construcción sismo resistente, 2010. Bogotá, DC.

[44] A. Neville, Core tests: easy to perform, not easy to interpret, Concr. Int. 23 (2001) 59-68. 